\title{
Histaminergic Descending Inputs to the Mesopontine Tegmentum and their Role in the Control of Cortical Activation and Wakefulness in the Cat
}

\author{
Jian-Sheng Lin, Yiping Hou, Kazuya Sakai, and Michel Jouvet \\ Département de Médecine Expérimentale, Institut National de la Santé et de la Recherche Médicale U52, Centre National \\ de la Recherche Scientifique 1195, Faculté de Médecine, Université Claude Bernard, 69373 Lyon Cedex 08, France
}

We have demonstrated previously the importance of histaminergic neurons in arousal mechanisms. In addition to their ascending axons, these neurons also send heavy descending inputs to the mesopontine tegmentum (MPT), which plays a key role in cortical activation during wakefulness $(\mathrm{W})$. This anatomical link suggests histaminergic control of the mechanisms of the MPT relevant to behavioral states. In this study, we sought to demonstrate, at the light microscopy level, hypothalamotegmental histaminergic pathways and their topographical interaction with MPT neurons in the cat and to explore further their involvement in sleep-wake control. Using immunohistochemistry of histamine $(\mathrm{HA})$, either alone or together with that of choline-acetyltransferase or tyrosine hydroxylase, a large number of very fine, short and varicose HA-positive fibers and terminal-like dots were detected in the MPT, including the laterodorsal tegmental nucleus, locus coeruleus (LC), LC $\alpha$, and peri-LC $\alpha$. Furthermore, these fibers and terminal-like structures were found in close proximity to a great number of cholinergic or noradrenergic neurons. We also investigated the effects of microadministration of HA agonists and antagonist into the mediodorsal pontine tegmentum on the cortical electroencephalogram (EEG) power spectra and the sleep-wake cycle in freely moving cats. Microinjection of $\mathrm{HA}$ or 2-thiazolylethylamine (an $\mathrm{H}_{1}$-receptor agonist) caused a longlasting suppression of cortical slow activity and an increase in quiet wakefulness (W). Paradoxical sleep, however, was less affected. The effects of HA were attenuated by systemic or in situ pretreatment with mepyramine (an $\mathrm{H}_{1}$-receptor antagonist), which when injected alone produced an increase in slow wave sleep. Microinjection of impromidine (an $\mathrm{H}_{2}$-receptor agonist) into the same area had no effect on either the cortical EEG or W.

Because MPT ascending and presumed cholinergic neurons discharge tonically during cortical activation of $W$ and because HA causes excitation of MPT cholinergic neurons via $\mathrm{H}_{1}$ receptors, we hypolhesize that the histaminergic descending afferents in the MPT would promote cortical desynchronization and $W$, at least partially, via activation of $H_{1}$ receptors situated on cholinergic neurons and that the interactions between histaminergic and cholinergic neurons constitute an important circuit in cortical activation during $W$.

Key words: histaminergic neurons; posterior hypothalamus; mediodorsal pontine tegmentum; mesopontine cholinergic neurons; noradrenergic neurons; locus coeruleus; microdialysis
From classical investigations, it is generally believed that the maintenance of cortical activation [or desynchronization, one of the most characteristic signs of wakefulness (W) and paradoxical sleep (PS)] requires ascending excitatory influx from the brainstem. Indeed, in acute preparations of high brainstem transection (Bremer, 1935) or isolated forebrain, the cortical electroencephalogram (EEG) displays a continuous high amplitude and slow activity (synchronization). Cortical activation is explained, therefore, by a generally accepted and long-standing concept, i.e., the reticular ascending activating system, proposed initially by Moruzzi and Magoun (1949) and supported by recent experimental data (Steriade and Glenn, 1982). According to this concept, the main ascending excitatory sources originate from the neuronal

\footnotetext{
Received Aug. 8, 1995; revised Nov. 10, 1995; accepted Nov. 17, 1995

This work was supported by the Centre National de la Recherche Scientifique (UA1195), Institut National de la Santé et de la Recherche Médicale (U52), DRET (Grant 91-215), and Université Claude Bernard. Part of the results were presented at the Eighth Annual Meeting of The Association of Professional Sleep Societies (Boston, 1994). We thank Drs. H. Onoé, P. Fort, and P. H. Luppi for useful discussion, Mr. G. Debilly for help in data analysis, and Ms. V. Cucchiaro for secretarial assistance.

Correspondence should be addressed to Jian-Sheng Lin, Département de Médecine Expérimentale, INSERM U52, CNRS 1195, Faculté de Médecine, Université Claude Bernard, 8 Avenue Rockefeller, 69373 Lyon Cedex 08, France.

Copyright (C) 1996 Society for Neuroscience $0270-6474 / 96 / 161523-15 \$ 05.00 / 0$
}

elements within the reticular formation of the brainstem and essentially transit in the thalamic relay to activate finally the whole cortex by a widespread thalamocortical system (Moruzzi, 1972; Steriade, 1991).

If the reticulothalamocortical pathway remains one of the most important substrates for ascending cortical activation, it can no longer be considered solely responsible, because cortical EEG desynchronization may reappear after extensive cellular destruction of the mesencephalic reticular formation (Denoyer et al., 1991) or its thalamic relay (Naquet et al., 1965; Angeleri et al., 1969; Villablanca, 1974; Buzsaki et al., 1988; Vanderwolf and Stewart, 1988). It is reasonable, therefore, to imagine the existence of one or several extrathalamic systems capable of activating the cortex, especially in the case of a deficit of the reticulothalamocortical system. Of these systems, the cholinergic basal forebrain has received particular attention (Steriade and Buzsaki, 1990). In addition, recent studies support the involvement of histaminergic neurons, a cell group more rostral to the classically defined reticular system, in cortical activation.

Indeed, histaminergic perikarya are located in the tuberomammillary nucleus (TM) and adjacent areas of the posterior hypothalamus, a brain area known to be important in waking mechanisms, because its pathological or experimental lesions cause 
hypersomnia (Moruzzi, 1972; Sallanon et al., 1988). These neurons send widespread axons to diverse brain areas known for their importance in sleep-wake processes such as the cortex, thalamus, and preoptic/anterior hypothalamus (Lin et al., 1986a, 1993; Inagaki et al., 1988; Panula et al., 1989). In freely moving cats, presumed histaminergic neurons discharge tonically and specifically during W (Vanni-Mercier et al., 1984; Sakai et al., 1990a; Krilowiicz et al., 1995). An increased release of histamine (HA) in the posterior hypothalamus of monkeys occurs on awakening and is maintained during each waking episode (Onoé et al., 1992b). Systemic administration of various substances impairing brain HA transmission causes an increase in slow wave sleep (SWS), whereas enhancement of transmission promotes W (Lin et al., 1986b, 1990; Monti et al., 1991). Inactivation of neurons, including HA cells, in the postcrior hypothalamus by muscimol (a GABA agonist) induces hypersomnia in normal cats and those rendered insomniac by various experiments such as $p$-chlorophenilalanine administration (Lin et al., 1989) or lesions of the preoptic/anterior hypothalamus (Sallanon et al., 1989). Finally, inhibition of HA synthesis in the same area increases SWS, whereas inhibition of its degradation elicits long-lasting arousal (Lin et al., 1988). Therefore, histaminergic neurons seem to be a probable neuronal substrate of the posterior hypothalamus involved in the maintenance of $W$.

Possible brain targets involved in this histaminergic arousal have been suggested by recent in situ pharmacological and in vitro electrophysiological studies. We have suggested that histaminergic neurons might enhance $\mathrm{W}$ by exerting a tonic control over the sleep-generating mechanisms of the preoptic/anterior hypothalamus (Lin et al., 1994). In addition, intracellular recording studies on brain slices have revealed that activation of $\mathrm{H}_{1}$ receptors in different target areas such as cortical neurons (Reiner and Kamondi, 1994), thalamic relay neurons (McCormick and Williamson, 1991), and basal forebrain cholinergic neurons (Khateb et al., 1995) causes a switch of neuronal discharge from rhythmic burst to single tonic activity and might thereby promote the alternation from SWS to W. On the other hand, activation of $\mathrm{H}_{2}$ receptors on thalamic, cortical, and hippocampal neurons elicits either an enhancement of hyperpolarization current or an abbreviation of afterhyperpolarization (McCormick and Williamson, 1989; Haas, 1992) and may therefore facilitate cortical and hippocampal neuronal activity. These results suggest that histaminergic neurons may promote cortical activation and $\mathrm{W}$, either directly via their hypothalamocortical projections or indirectly via other ascending pathways to the thalamus, preoptic area, and substance innominata, structures that control sleep-wake alternation.

However, histaminergic neurons send out not only ascending projections but also descending pathways to the brainstem (Inagaki et al., 1988; Panula et al., 1989; Lin et al., 1993). Moreover, anatomical tracing studies in the cat (Sakai et al., 1977, 1983) have demonstrated a neuronal projection from the posterior hypothalamus to the mesopontine tegmentum (MPT), which contains cholinergic, noradrenergic, and other neuronal populations playing a key role in the generation of diverse phenomena of $W$ and PS (Jouvet, 1972; Jones, 1990; Sakai et al., 1990a; Steriade et al., 1990). This anatomical link suggests possible histaminergic control of the mechanisms of the MPT relevant to behavioral states, a hypothesis worthy of verification, especially if one considers that during the development of concepts regarding mechanisms of cortical activation, the role of descending systems has not yet been investigated. Therefore, the present study was designed to demonstrate the existence of hypothalamotegmental histaminergic pathways and their topographical interaction with cholinergic and noradrenergic neurons at the light microscopic level, using immunohistochemical double-staining, and to explore further their functional role in cortical activity and the sleep-wake cycle by an in situ pharmacological approach coupled with polygraphic recordings and spectral analysis of the cortical EEG.

\section{MATERIALS AND METHODS}

Immunohistochemical localization of histaminergic descending inputs and cholinergic or noradrenergic neurons in the MPT. Six adult cats were deeply anesthetized with pentobarbital $(25 \mathrm{mg} / \mathrm{kg}$, i.v.) and perfused through the ascending aorta with $1 \mathrm{l}$ of Ringer's lactate solution containing $0.1 \%$ heparin, followed by 1.51 of ice-cold $0.1 \mathrm{~m}$ phosphate buffer (PB), pH 7.4, containing $1 \% p$-formaldehyde and 4\% 1-ethyl-3(3diaminomethylpropyl) carbodiimide (Sigma, St Louis, MO). After overnight post-fixation in the same solution and rinsing for $48-72 \mathrm{hr}$ in $\mathrm{PB}$ containing $30 \%$ sucrose, the brains were coronally or sagittally sectioned ( 20 or $25 \mu \mathrm{m}$ thickness) on a freezing cryostat. Free-floating sections were then incubated for $72-96 \mathrm{hr}$ at $4^{\circ} \mathrm{C}$ on an agitator, with rabbit anti-HA antiserum (Instar, Stillwater, MN) (Panula et al., 1988) diluted 1:20,000 to $1: 50,000$ in PB saline containing $0.3 \%$ Triton X-100 (PBS-T) and $0.1 \%$ sodium azide. After rinses, the sections were submitted to one or two procedures as follows.

Sections were incubated with biotinylated anti-rabbit $\operatorname{IgG}(1: 2000)$ (Jackson Immunoresearch, West Grove, PA), and after several rinses they were placed in horseradish peroxidase-conjugated streptavidin (1:40,000; Jackson Immunoresearch). Both incubations were performed in $\mathrm{PBS}-\mathrm{l}$ at $4^{\circ} \mathrm{C}$ overnight on an agitator. The sections were then immersed in $0.05 \mathrm{M}$ Tris- $\mathrm{HCl}$ buffer, $\mathrm{pH} 7.6$, containing $0.02 \%$ $3,3^{\prime}$ diaminobenzidine $-4 \mathrm{HCl}(\mathrm{DAB}), 0.003 \% \mathrm{H}_{2} \mathrm{O}_{2}$, and $0.6 \%$ nickel ammonium sulfate for $10-15 \mathrm{~min}$ at room temperature. Positive reaction produced blue-black staining of the labeled structures (somata, dendrites, axons, and varicosities).

Some sections were immediately mounted on gelatin-coated glass slides, dried, and coverslipped with Depex for light microscopy to study the histaminergic descending fiber projections in the brainstem.

Other sections were processed for dual-color immunostaining. After many rinses in PBS-T, these pretreated sections were incubated, as described above, but with a goal anti-choline-acetyltransferase (ChAT) antiserum (CA92590; Chemicom, Temecula, CA) or a rabbit antityrosine hydroxylase (TH) antiserum (Institut Jacques Boy, Reins, France), diluted 1:5000 to $1: 20,000$. In addition, in this second series of immunostaining, the streptavidin procedure was replaced by the classical peroxidase-antiperoxidase $(1: 800$ to $1: 1000)$ method (Sternberger and Joseph, 1979). At the end of the incubation, the sections were incubated with $0.05 \mathrm{M}$ Tris- $\mathrm{HCl}$ buffer, $\mathrm{pH} 7.6$, containing $0.025 \% \mathrm{DAB}$ and $0.006 \%$ $\mathrm{H}_{2} \mathrm{O}_{2}$ for 15-30 min at room temperature, producing light brown reaction products. Thus, after these dual sequential immunoreactions, histaminergic descending fibers and terminal-like dots displayed a blue-black color, whereas $\mathrm{Ch} \Lambda \mathrm{T}$ - or TH-containing neurons stained a light brown color. Finally, the sections were prepared for observation with light microscope. The atlases of Reinoso-Suárez (1961) and Berman (1968) were used for the anatomical nomenclature of cerebral regions and for their abbreviations. For the description of the mesopontine tegmental structures containing cholinergic, monoaminergic, and other neurons, however, we used the nomenclatures defined by Maeda et al. (1973) and Sakai $(1980,1991)$ such as laterodorsal tegmental nucleus (Ldt), locus coeruleus nucleus (LC), LC $\alpha$, and peri-LC $\alpha$ (equivalent to the sublaterodosal nucleus, defined in the rat by Swanson, 1992). In the cat, the peri-LC $\alpha$ is distinct from the Ldt and pedunculopotine tegmental nucleus (PPT) by its location, and cyto- and chemoarchitecture, as well as by its afferents and efferents (see details in Sakai, 1980, 1991).

In situ pharmacological approach in the dorsal pontine tegmentum, polygraphic recordings, and spectral analysis of ncocortical EEG. Twentyone adult cats of both sexes, weighing $2.7-3.5 \mathrm{~kg}$, were chronically implanted, under pentobarbital anesthesia $(25 \mathrm{mg} / \mathrm{kg}$, i.v.), with electrodes for polygraphic recordings of the pontu-geniculo-occipital (PGO) activity, electromyogram, electrooculogram, and EEG of the neocortex, hippocampus, and olfactory bulb. In addition, stainless steel guide cannulae [outside diameter (o.d.) $0.6-0.8 \mathrm{~mm}$ ] with indwelling stylets were implanted bilaterally so that their tips were $5 \mathrm{~mm}$ above the dorsal pontine tegmentum at coordinates of A1-P3, L1.5-L3, and Hc6-Hc7.5, according to the atlas of Reinoso-Suárez (1961). In several animals, a thermistor $\left(10 \mathrm{~K} 3 \mathrm{MCD} 2\right.$, Betatherm, Lagny, France; $10 \mathrm{k} \Omega$ at $25^{\circ} \mathrm{C}$, o.d. 
$0.45 \mathrm{~mm}$ ) was placed in the caudate nucleus to record brain temperature. In others, a small thermocouple was placed under the deep neck muscles to record body temperature. After a recovery period of $7 \mathrm{~d}$, the animals were houscd in a sound-attenuated and dimly illuminated cage at 24$27^{\circ} \mathrm{C}$ and were fed twice daily, at 9 A.M. and 6 P.M. To obtain control recordings, the "injection simulation" (without inserting the injection needle) was carried out at 11 A.M. during the first $4-5 \mathrm{~d}$.

Microinjections were performed at 11 A.M. by conventional or microdialysis techniques. (1) A $1 \mu$ l Exmire microsyringe (MS-01U) was used. The needle of the syringe (o.d. $0.4 \mathrm{~mm}$, ground to $0.3 \mathrm{~mm}$ at the tip) extended $5 \mathrm{~mm}$ past the tip of the guide cannula. Injection lasted $1 \mathrm{~min}$, and the needle of the syringe was maintained in place for an additional minute. (2) A basic microprocessor-controlled syringe pump (Harvard 22, Harvard Instruments, Boston, MA) was used. It was connected with the injection needle (o.d. $0.3 \mathrm{~mm}$ ) by a catheter through a small-animal cannula swivel (mF-5/25, CMA/110, Bioanalytical Systems, West Lafayette, IN), permitting injections at a distance without disturbing the free movements and ongoing bchavioral statcs of the animal. All injections (not more than 4 per injection site) were bilateral. There was an interval of $7 \mathrm{~d}$ between administrations. (3) A microdialysis probe (length of dialysis membrane $1 \mathrm{~mm}$; $0 . d .0 .24 \mathrm{~mm}$; CMA/Microdialysis AB, CMA/ 11, Bioanalytical Systems) was used to examine the effects of HA applied by dialysis membrane exchange instead of by conventional injection. The in vivo microdialysis technique has several advantages, including the allowance of continuous perfusion of a discrete cerebral area with soluble pharmacological substances without sudden injection of a concentrated volume of fluid into the brain (Juhasz et al., 1990; Onoé et al., 1992a). In brief, the microdialysis probe was inserted unilaterally and fixed through the implanted guide cannula into the MPT of three animals. The probe was perfused continuously with Ringer's solution at a rate of $2-5 \mu \mathrm{l} / \mathrm{min}$ using the same syringe pump (Harvard 22) through a liquid switch and a dual-channcl hydraulic swivel. The microdialysis systcm was attached to a slip-ring for polygraphic recordings, allowing the cats to move freely in the recording cage. The probe was maintained in the brain for $4-6 \mathrm{~d}$.

Polygraphic records subsequent to "simulation" or microadministration were made for at least $24 \mathrm{hr}$. They were scored minute by minute according to previously described criteria (Petitjean et al., 1975) for W, light SWS (SWS1), deep SWS (SWS2), and PS. A daily $22 \mathrm{hr}$ recording period (11 A.M. to 9 A.M. the next day) was used for statistical analyses because the sleep-wake cycle of the cats was usually disturbed from 9 to 10 A.M. when their cages and skull electrode assemblies were cleaned. In some animals, the neocortical and hippocampal EEG signals during the $6 \mathrm{hr}$ after control injection or drug administration were digitized at a sample rate of $100 \mathrm{~Hz}$ and computed on a CED 1401 Plus (Cambridge, UK). The power spectral density was averaged over $31 \mathrm{sec}$ epochs for the frequency range of $0.25-50 \mathrm{IIz}$ by a fast Fourier transform routine using the CED program Spike2.

The paired Student's $t$ test (two-tailed) was used to analyze the differences in the sleep-wake cycle between simulation controls and saline injections, as well as between saline and drug microinjections. In both cases, individual animals served as their own controls. All differences in the sleep-wake parameters after drug injection are expressed relative to saline injection controls.

The drugs used were mepyramine maleate (pyrilamine; Sigma), HA dihydrochloride (Sigma), impromidine trihydrochloride (SKF, Garden City, Herts, UK), 2-thiazolylethylamine dihydrochloride (2-TEA; SKF), and sodium nitrite (Fluka, Buchs, Switzerland). For microinjection, all drug doses were expressed as their salt weights, dissolved in 0.25 or $0.5 \mu \mathrm{l}$ of physiological saline immediately before use. For microdialysis, HA ( 0 , 1,5 , and $10 \mathrm{~mm}$ ) was dissolved in Ringer's solution and perfused at a rate of $5 \mu \mathrm{l} / \mathrm{min}$.

At the end of the experiments, the animals were deeply anesthetized and perfused with $0.1 \mathrm{M}$ PB containing 1-ethyl-3(3-diaminomethylpropyl) carbodiimide $(1-4 \%$; Sigma) or $p$-formaldehyde $(1-2 \%)$ or both as fixatives. Injection loci were determined using standard histological methods. The brains of some animals were processed for HA immunocytochemistry, according to the procedures described above, to visualize HA fibers and terminal-like structures around the injection loci.

\section{RESULTS}

Histaminergic descending pathways to the MPT and local fiber density

As reported previously in the cat (Lin et al., 1986a, 1991, 1993; Uhlrich et al., 1993), most HA-immunoreactive (-ir) cell bodies aggregate in the TM and the adjacent lateral hypothalamic area (Fig. 1), as well as in the peri- and supramammillary areas. As is the case with ascending projections, HA descending fibers are more dense in the median part of the brainstem than in the lateral part. In parasagittal sections, it was possible to trace descending axons emanating from histaminergic perikarya. In addition to a large number of scattered fibers, two principal bundles could be distinguished.

The ventral descending bundle was identified both medially and laterally in the mesencephalon. As shown in a drawing section at approximately L2.5 (Fig. 1), a loose bundle of HA fibers left the caudal two thirds of the TM nucleus and its more dorsal adjacent areas to run in the ventral part of the mesencephalon, passing through the ventral tegmental area of Tsai in an almost horizontal direction. Some fibers were directed more ventrally to form a dense network within the substantia nigra, whereas a large part of the axon bundle turned dorsally just at a level caudal to the red nucleus and then ran almost vertically. These dorsally directed axons then coursed along the junction between the central tegmental field (FTC) and the gigantocellular tegmental field (FTG) to reach the mesopontine periaqueductal gray and the dorsal tegmentum, including the pedunculopontine area and LC. Some fibers passed through the brachium conjunctivum (BC) to innervate the most dorsal part of the pontine reticular formation, i.c., the $\mathrm{LC} \alpha$ and peri-LC $\alpha$ regions (Fig. 1). More medially at approximately L0.5-L1.0, massive fibers, running in the ventral descending bundle, terminated in the periaqueductal gray and the raphe nuclei (not shown).

The dorsal descending bundle was more prominent medially (L0.5-L1.0) than laterally (L2.0-L3.0). Only a section of the lateral brainstem (Fig. 1) is shown here. Fewer axons were seen at this level than in the ventral descending bundle. Arising from all parts of the HA neuronal group, these axons first ran within the hypothalamus in a dorsal direction. After passing through the zona incerta, they scattered in several directions. Some oriented vertically to reach the thalamus, including different intralaminar nuclei; others turned progressively caudally and laterally toward the dorsal part of the mesencephalic reticular formation to reach finally the superior and inferior colliculi and the MPT, including the mesopontine periaqueductal gray, LC, and Ldt (Fig. 1). The LC $\alpha$ and peri-LC $\alpha$ regions were innervated mainly by laterally directed, scattered, and fine fiber terminals from this bundle, seen in horizontal and frontal sections.

In frontal sections, a dense HA-ir fiber network was detected in the MPT. Numerous relatively long and varicose fibers were present in the LC and Ldt and other zones of the periaqueductal gray. Many ran ventrolaterally, penetrating into the $\mathrm{LC} \alpha$ and peri-LC $\alpha$ regions (Fig. 2A). The number and density of these fibers decreased significantly in the more ventral zone of the reticular formation (i.e., FTG), suggesting that large HA fibers terminate in the $\mathrm{LC} \alpha$ and peri-LC $\alpha$. Moreover, the HA nerve fibers in these structures were very fine and short and endowed with very prominent varicosities, and they seemed to form a large number of terminal-like dots (Figs. $2 A, B, 3,4$ ).

\section{Interactions of HA fibers and terminals with cholinergic and noradrenergic neurons in the MPT}

When HA-immunoreacted sections were subsequently treated with ChAT immunohistochemistry, ChAT-ir (cholinergic) neurons were observed in the pedunculopontine area, Ldt, LC $\alpha$, and peri-LC $\alpha$ (Fig. $3 A$ ), in accordance with previous reports in 


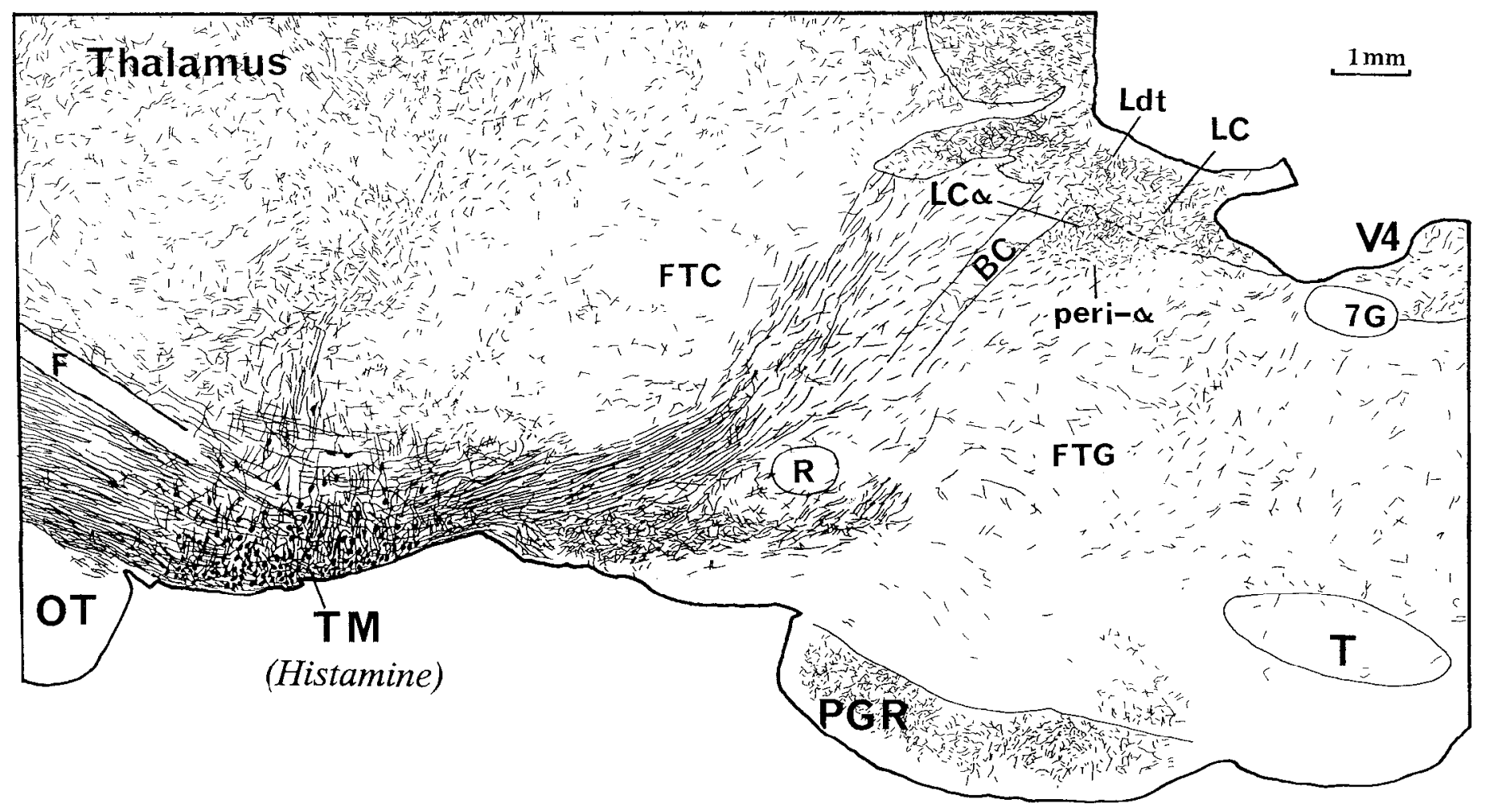

Figure 1. Histaminergic descending projections in the lateral brainstem of cats. Camera lucida drawing of HA-ir neurons from a brainstem párasagittal section near L2.5 showing the location of HA cell bodies in the tuberomammillary nucleus (TM) and adjacent areas. Note that these neurons give rise to the following: (1) the ventral descending bundle running initially in the ventral part of the mesencephalon and then in the junction between the central tegmental $(F T C)$ and gigantocellular tegmental $(F T G)$ fields to reach the MPT, including the laterodorsal tegmental nucleus $(L d t)$, locus coeruleus $(L C)$, $L C \alpha$, and peri-LC $\alpha$ (peri- $\alpha)$; and (2) the root of the dorsal descending bundle in the hypothalamus. The dorsal descending bundle is more prominent in more medial planes. $B C$, Brachium conjunctivum; $F$, fornix; $O T$, optic tract; $P G R$, pontine gray, retroventral division; $R$, red nucleus; $T$, nucleus of the trapezoid body; V4, fourth ventricle; and $7 G$, genu of the facial nerve. Please refer back to this figure for abbreviations in subsequent figures. Scale bar, $1 \mathrm{~mm}$.

the cat (Sakai et al., 1986; Jones and Beaudet, 1987; Vincent and Reiner, 1987). In these structures, a large number of HA fibers and terminal-like dots was found in close proximity to cholinergic neurons and seemed to make contact with them (Fig. 3). Because ChAT immunostaining in the dendrites was not as dense as that in the soma; many HA-varicose fibers and terminal-like dots seemed to be in close proximity to the soma of the cholinergic cells, whereas those in close vicinity with their dendrites were observed less frequently (Fig. 3B,C).

Similarly, when sections were processed for TH immunoreactivity, $\mathrm{TH}$-ir (noradrenergic) neurons were found to be located in the LC, LC $\alpha$, subcoeruleus nucleus, and adjacent structures (Fig. 4A), as reported previously (Maeda et al., 1973; Wiklund et al., 1981; Jones and Beaudet, 1987). A large number of HA fibcrs and tcrminal-like dots was found in proximity to noradrenergic neurons and seemed to make contact with them (Fig. $4 A, B$ ). Both the soma and dendrites of the noradrenergic neurons were stained densely by TH immunocytochemistry and HA-varicose fibers, and terminal-like dots could be seen in proximity to both the soma and dendrites of noradrenergic cells in the LC and LC $\alpha$. Furthermore, individual cholinergic or noradrenergic cells, especially those of medium to large size, seemed to be encircled frequently by several HA fibers or terminal-like dots, or by several varicosities of a single terminal-like fiber.

\section{Effects on cortical EEG and the sleep-wake cycle after microadministration of HA agonists and antagonist into the mediodorsal pontine tegmentum}

In pilot assays, HA was injected bilaterally into different loci of the mediodorsal pontine tegmentum rostrocaudally from the A0 to P3 planes of the atlas of Reinoso-Suárez (1961), including the $\mathrm{Ldt}, \mathrm{LC}, \mathrm{LC} \alpha$, and peri-LC $\alpha$. Injection into the area between the LC and peri-LC (Figs. $2 A, 3 A$ ) was found to cause the greatest degree of EEG desynchronization and $W(1.5-2.5$ hr of total $\mathrm{W})$, whereas injection into the areas near the LC or Ldt induced an incomplete waking state lasting $0.5-1.5 \mathrm{hr}(n=$ 3 for both). Subsequent injections were focused on $\mathrm{LC} \alpha$ and peri-LC $\alpha$ loci at coordinates P1-P2, L2.5, and Hc7 (Fig. 3A, arrow). As described above, this area contains a high density of very fine, short, and varicose $\mathrm{H} \Lambda$ ir fibers and abundant terminal dot-like structures (Fig. 2). It also contains a high number of ChAT-ir neurons and, to a lesser degree, TH-positive neurons (Figs. 3, 4). The following results, obtained using HA agonists and antagonist, were compared with those obtained in the same animals using injections of $0.9 \% \mathrm{NaCl}(0.25-0.5 \mu \mathrm{l}, n$ $=15$ ) or Ringer's solution (for microdialysis, $5 \mu \mathrm{l} / \mathrm{min}, n=5$ ), which had no significant effect on the sleep-wake parameters and cortical activity (Figs. 5, 6A, 7A). No microinjections conducted in this area had any significant effect on brain or body temperature. 

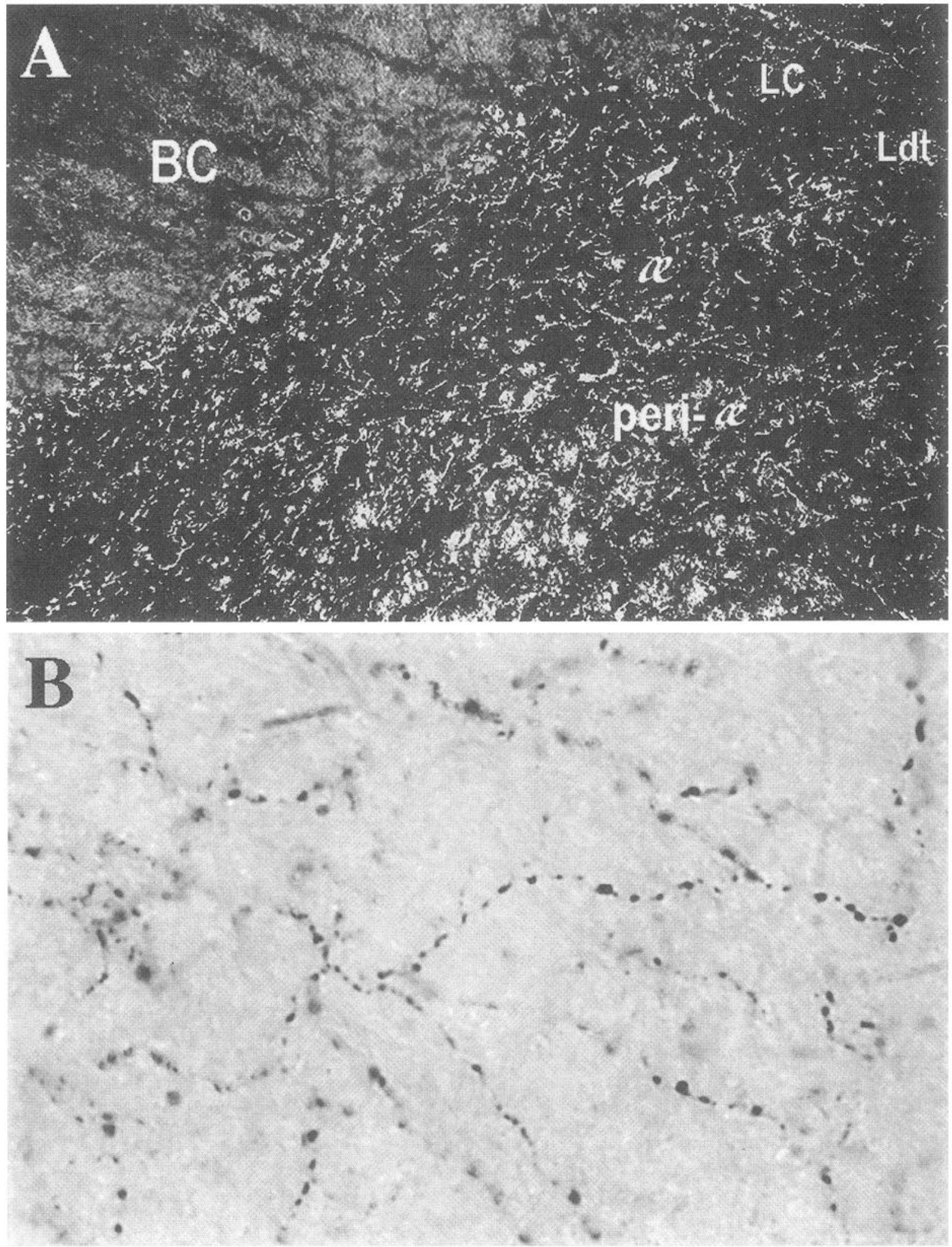

Figure 2. Distribution and morphology of histaminergic fibers in the cat dorsal pontine tegmentum. $A$, Dark-field photomicrograph (with the aid of an orange filter) with low-power magnification of a frontal section showing the distribution and density of very fine and short HA-ir fibers in different structures within the MPT, including the $\mathrm{LC} \alpha(L C)$ and peri-LC $\alpha$ (peri- $\alpha)$ regions. $B$, Photomicrograph with high-power magnification of the area between $\mathrm{LC} \alpha$ and peri-LC $\alpha$ showing the varicosity of HA-ir fibers and terminal-like dots. See Figure 1 for abbreviations. Scale bar: $A, 50 \mu \mathrm{m} ; B, 10 \mu \mathrm{m}$. 

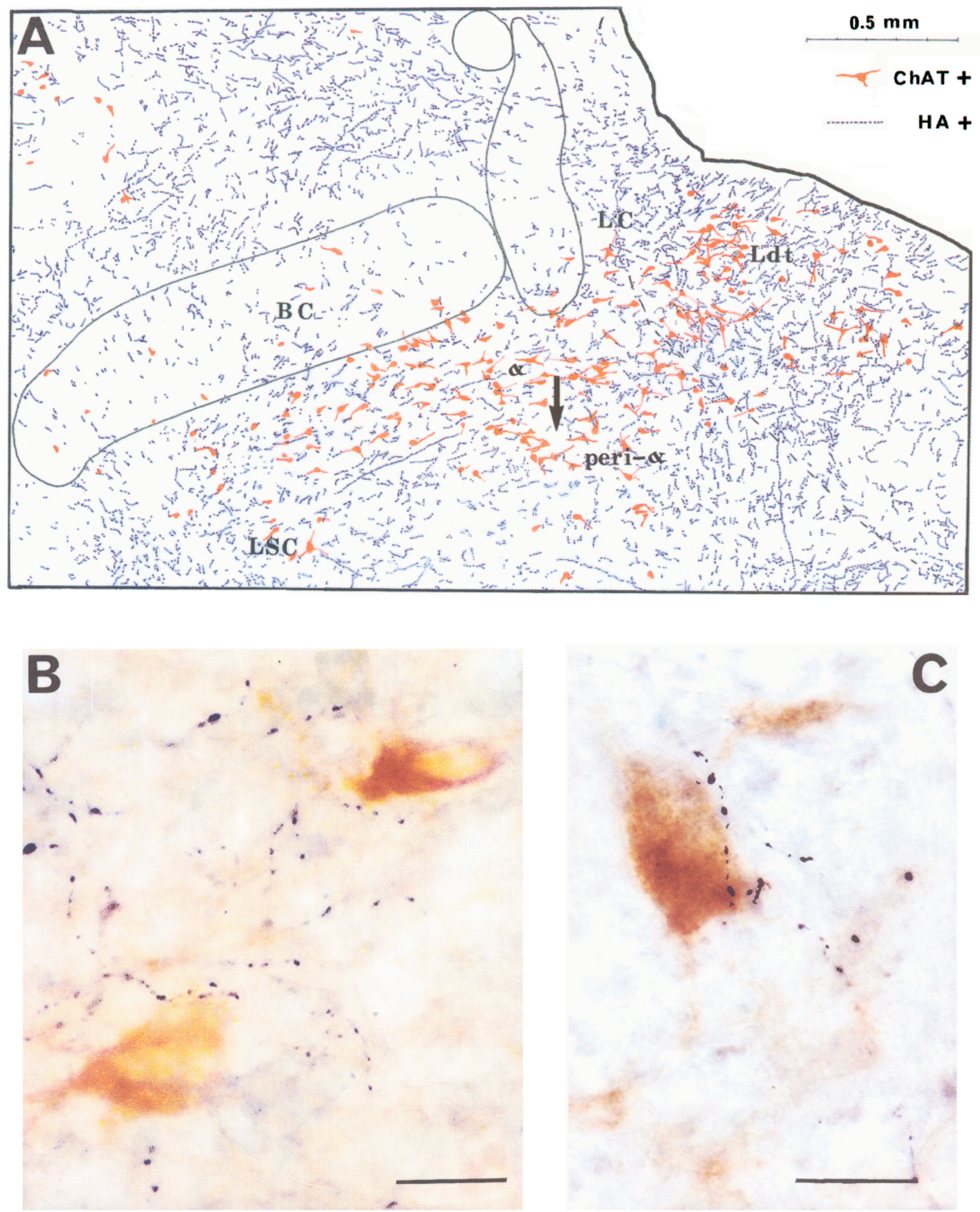

Figure 3. Topographic interactions of HA descending fibers with cholinergic neurons in the cat dorsal pontine tegmentum. $A$, Camera lucida drawing of a double (HA and ChAT)-immunoreacted frontal section showing the codistribution of HA-ir fibers (blue) and cholinergic neurons (red) in the MPT. $L S C$, nucleus locus subcoeruleus. See Figure 1 for other abbreviations. $B, C$, Photomicrographs of the region between the LC $\alpha$ and peri-LC $\alpha$. Note the proximity of HA varicose fibers (blue) to cholinergic perikarya (brown) and probable contacts between them. In $A$, the number of cholinergic cells approached by HA fibers was estimated at $\sim 70.5 \%$ under light microscope. The injection site of our in situ pharmacological study is also indicated in $A$ by an arrow. Scale bar: $B, C, 25 \mu \mathrm{m}$. 

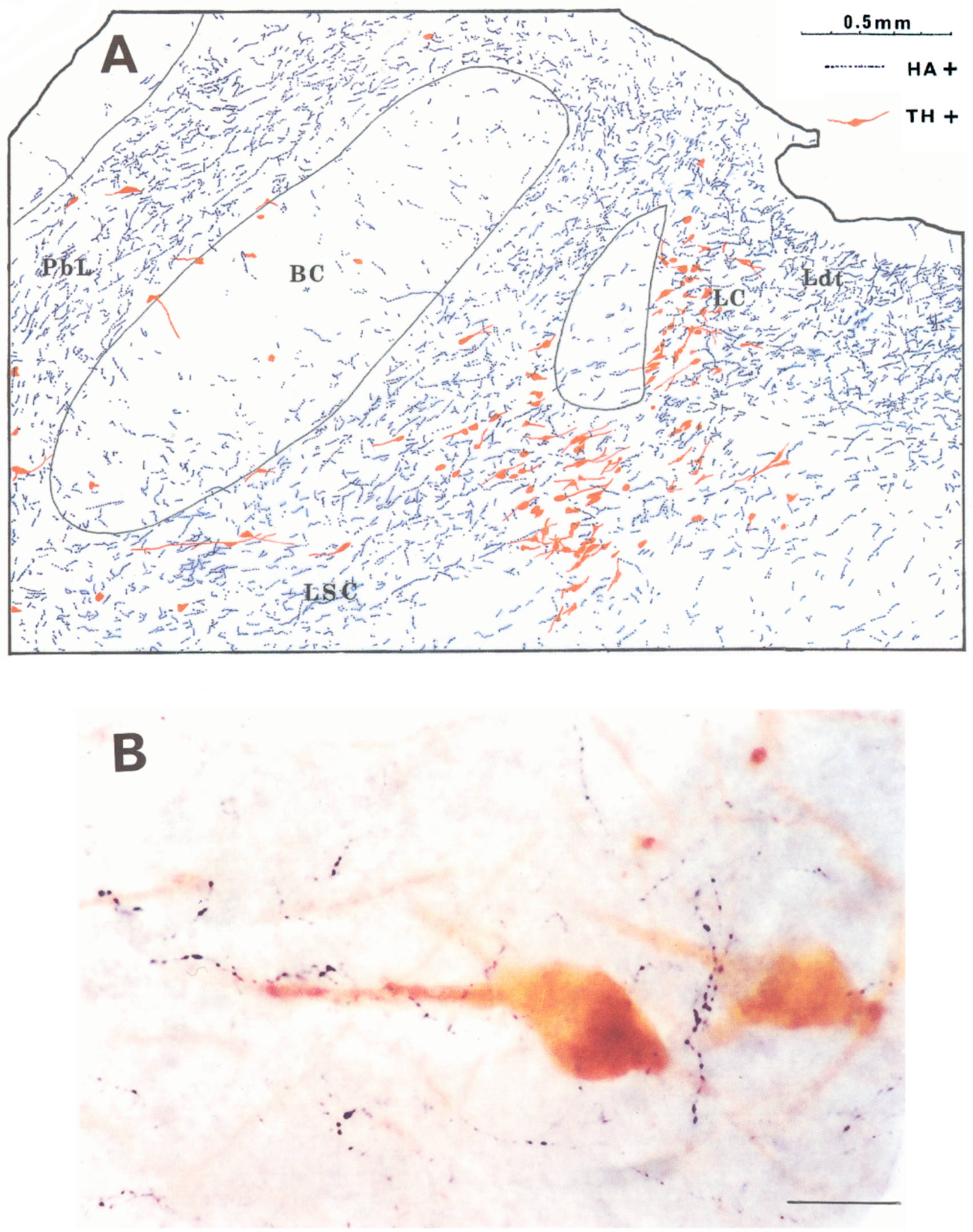

Figure 4. Topographic interactions of HA descending fibers with noradrenergic neurons in the cat dorsal pontine tegmentum. $A$, Camera lucida drawing of a double ( $\mathrm{HA}$ and $\mathrm{TH})$-immunoreacted frontal section showing the codistribution of HA-ir fibers (blue) and noradrenergic neurons (red) in the $L C$ and $\mathrm{LC} \alpha . B$, Photomicrographs of the region of the $\mathrm{LC} \alpha$. Note the proximity of HA varicose fibers (blue) to the noradrenergic cells (brown) and probable contacts between them. In $A, \sim 62.7 \%$ of noradrenergic neurons seemed to be approached by HA fibers, estimated under light microscope. $P b l$, nucleus parabrachialis lateralis; $L S C$, nucleus locus subcoeruleus. See Figure 1 for other abbreviations. Scale bar ( $\operatorname{shown}$ in $B$ ), $25 \mu \mathrm{m}$. 

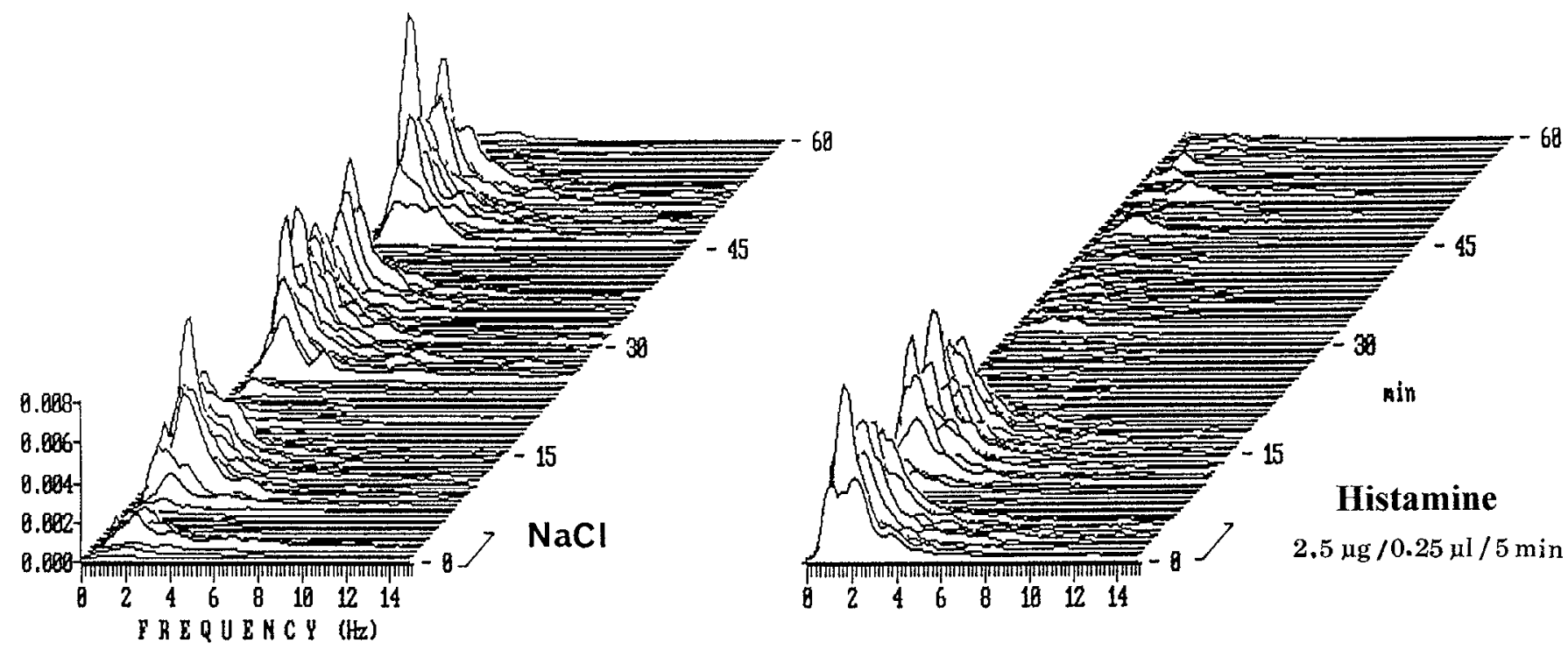

Figure 5. Effects on power spectral density of the neocortical EEG after distant infusion of HA into the cat mediodorsal pontine tegmentum. The EEG spectra were obtained by fast Fourier transformation within $60 \mathrm{~min}$ of administering the saline $(0.9 \% \mathrm{NaCl})(A)$ or $\mathrm{HA}(B)$ at a dose of $2.5 \mu \mathrm{g} / 0.25 \mu \mathrm{l}$, perfused for $5 \mathrm{~min}$ during SWS2. Note the suppression of cortical slow activity $(0.5-5 \mathrm{~Hz})$ and spindles $(8-14 \mathrm{~Hz})$ induced by $\mathrm{HA}$ after a latency of $\sim 10$ min: $x$-axis, EEG frequency in $\mathrm{Hz} ; y$-axis, EEG power in $\mathrm{mV}^{2} ; z$-axis, time in minutes.

\section{HA}

Both microinjection $(2.5-15 \mu \mathrm{g}$ in $0.25-0.5 \mu$; Figs. 5, 7D) and microdialysis (5-10 $\mathrm{mM}, 5 \mu \mathrm{l} / \mathrm{min}$; Fig. 6) of HA into the mediodorsal pontine tegmentum caused suppression or diminution (depending on the doses used) of neocortical slow activity $(0.8-4$ $\mathrm{Hz})$ and spindles $(8-14 \mathrm{~Hz})$, causing a state of long-lasting cortical desynchronization, i.e., low-voltage electrical activity with dominant waves in the $\beta$ - and $\gamma$-bands (mainly $20-40 \mathrm{~Hz}$ ). Furthermore, HA increased the power density of these neocortical fast rhythms (Fig. 6B).

These effects were manifested on polygraphic scoring as an almost permanent state of quiet $\mathrm{W}$ (Figs. $6 B, 7 D$ ), the duration of which was dose-dependent (e.g., $1.5-2.5 \mathrm{hr}$ for a dose of $5 \mu \mathrm{g} / 0.25$ $\mu \mathrm{l}, n=8$, and $3-5 \mathrm{hr}$ for a dose of $15 \mu \mathrm{g} / 0.5 \mu \mathrm{l}, n=5$ ). During this period, SWS, especially SWS2, was totally suppressed. PS diminished during the first $1-2 \mathrm{hr}$ recording period, but some episodes persisted, after the appearance of a few cortical spindles and hippocampal slow waves (Figs. 6B, 7D; Table 1). After these effects, cortical slow activity gradually reappeared (Fig. 6B), but the increase in duration of $\mathrm{W}$ persisted for $4-8 \mathrm{hr}$, depending on the doses used (Table 1). The waking effect of $\mathrm{HA}$ was attributable mainly to an increase in wake-episode duration and a delayed sleep latency. At the end of the $22 \mathrm{hr}$ period, the time spent in $\mathrm{W}$ or SWS had returned almost to control levels, whereas a slight rebound in PS was seen (Table 1).

It should be noted that injections made in the more rostral sites (P1), i.e., the $\mathrm{LC} \alpha$ and peri- $\mathrm{LC} \alpha$ regions rich in cholinergic neurons, caused a more complete EEG desynchronization and a more pronounced waking effect than those made in the more caudal sites (P2-P3) near the LC, where noradrenergic neurons are predominant. On the other hand, the cxtent of HA-induced W and cortical desynchronization in the mediodorsal pontine tegmentum was greater than that observed after its microinjection into the posterior hypothalamus or preoptic/anterior hypothalamus. For example, at a dose of $5 \mu \mathrm{g}$, HA injected into the mediodorsal pontine tegmentum, posterior hypothalamus, or preoptic/anterior hypothalamus increased $\mathrm{W}$ by 98,51 , and $68 \%$ (in comparison with time spent by the respective controls in W) for a $6 \mathrm{hr}$ recording period (see Table 1 and Lin et al., 1988, 1994).

HA is known to produce vasodilatation (Gross, 1982). We therefore used sodium nitrite, a potent vasodilator, to verify whether local vasodilatation of injection loci could mimic the arousal effect of IIA. Injection of sodium nitrite $(15-30 \mu \mathrm{g} / 0.5 \mu \mathrm{l}$, $n=4$ ) into the mediodorsal pontine tegmentum caused no significant increase in W when compared with saline injection data (not shown). These results suggest that HA-induced arousal is not attributable to its vasodilatory action.

\section{2-TEA}

Like HA, 2-TEA (15 $\mu \mathrm{g} / 0.5 \mu \mathrm{l}, n=4$ ), an HA agonist that is approximately fourfold less potent than $\mathrm{HA}$ on $\mathrm{H}_{1}$ receptors (Schwartz, 1979), evoked cortical desynchronization and a $61 \%$ increase in W during the first $3 \mathrm{hr}$ after injection, at the expense of SWS and PS (Fig. 7B; Table 1).

During the waking periods elicited by HA or 2-TEA, neither behavioral excitation nor signs of respiratory and cardiovascular disturbance were noted. For most of the time, the animals were sitting or lying down, moving around only occasionally. Their brain and body temperatures were similar to those observed during wake episodes of baseline recordings or after saline injection.

\section{Mepyramine}

In contrast to HA and 2-TEA, microinjection of mepyramine, a prototypical $\mathrm{H}_{1}$-receptor antagonist (Schwartz, 1979), at a dose of $5 \mu \mathrm{g} / 0.25 \mu \mathrm{l}(n=5)$ caused a decrease in duration of $\mathrm{W}$ and an increased duration of SWS, especially SWS2. PS increased slightly during the first $6 \mathrm{hr}$ rccording pcriod (Fig. 7C; Tablc 1). The observed quantitative increase in SWS did not seem to be attributable to the antimuscarinic property seen at high dose with the current $\mathrm{H}_{1}$-receptor antagonists, because injection of atropine, a muscarinic antagonist, into the same region induced different effects, i.e., suppression of PS and SWS2 (not shown) (VanniMercier et al., 1989). 

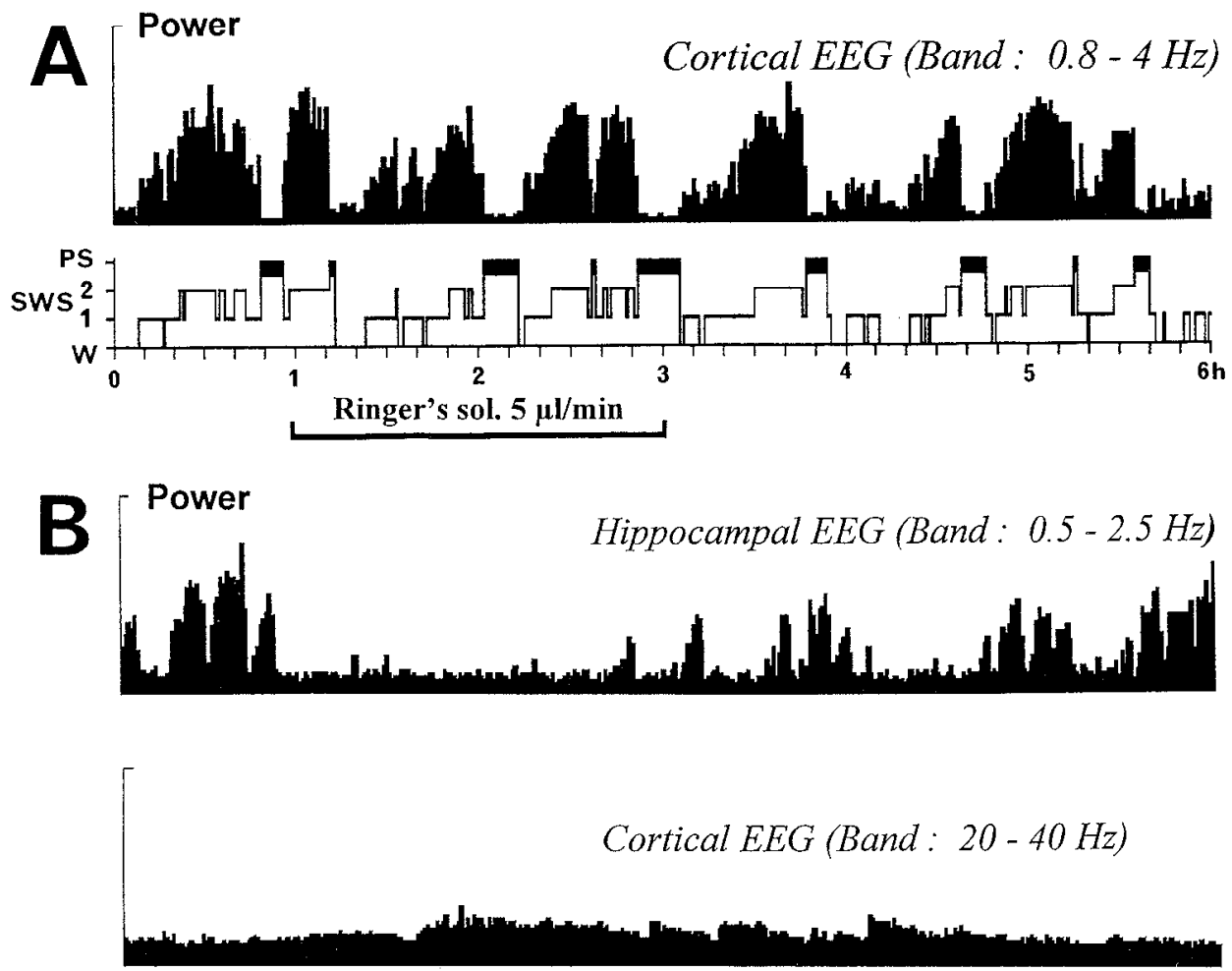

Figure 6 . Effects of $\mathrm{HA}$ application by microdialysis into the mediodorsal pontine tegmentum on cortical EEG and sleep-wake cycle in the cat. $A$, Neocortical EEG power density $\left(\mathrm{mV}^{2}\right)$ in slowfrequency bands $(0.8-4 \mathrm{~Hz})$ and $6 \mathrm{hr}$ hypnograms before, during (indicated by a solid line), and after perfusion ( 5 $\mu \mathrm{l} / \mathrm{min}$ ) of Ringer's solution alone. $R$, EEG power density $\left(\mathrm{mV}^{2}\right)$ and $6 \mathrm{hr}$ hypnograms before, during (indicated by a solid line), and after perfusion of Ring. er's solution containing $\mathrm{HA}(5 \mathrm{~mm}, 5$ $\mu \mathrm{l} / \mathrm{min}$ ), showing the onset, duration, and recovery of the effects of HA on different frequency bands of neocortical $(0.8-4,8-14$, and $20-40 \mathrm{~Hz})$ and hippocampal $(0.5-2.5 \mathrm{~Hz})$ EEG and on sleep-wake states. One hour control recordings of cortical spindles and fast rhythms and hippocampal EEG were provided before HA application. Note (from bottom to top): (1) the waking effect of HA and the persistence of paradoxical sleep $(P S)$ during the induced wakcfulness $(W) ;(2)$ the suppression of cortical slow-frequency activity $(0.8-4$ $\mathrm{Hz}_{z}$ ) and deep slow wave sleep (SWS2); (3) the marked decrease in cortical spindles $(8-14 \mathrm{~Hz})$ and light slow wave sleep (SWS1); (4) the increase in neocortical fast rhythms $(20-40 \mathrm{~Hz})$; and (5) the reappearance of slow-frequency activity of the hippocampus $(0.5-2.5 \mathrm{~Hz})$ before that of the cortex. Abscissa indicates time (in hr).

\section{HA after mepyramine pretreatment}

The arousal effects of HA $(5 \mu \mathrm{g})$ were attenuated by intraperitoneal $(1 \mathrm{mg} / \mathrm{kg}, n=4$; Fig. $7 E$ ) or in situ $(5 \mu \mathrm{g}, n=4$; Fig. $7 F)$ pretreatment with mepyramine administrated either 30 or 5 min before the local injection of HA, as shown by a decreased duration of $W$ and an increased duration of SWS when compared with HA microinjection alone (Fig. 7D; Table 1). Although the effects of HA on SWS were reversed totally by mepyramine during the $6 \mathrm{hr}$ recordings, its arousal effect was prevented only partially, persisting for the first $2 \mathrm{hr}$ and then decreasing significantly during the following period (Fig. 7; Table 1). This partial blockade might be attributable to a greater amount of the agonist (and thus more potent effect) than to that of the antagonist in the injection site, because only a weak dose of mepyramine was used.

\section{Impromidine}

When impromidine $(0.2 \mu \mathrm{g} / 0.25 \mu \mathrm{l})$, a potent agonist of $\mathrm{H}_{2}$ receptors (Durant et al., 1978), was injected into the mediodorsal pontine tegmentum, no significant effects were found on cortical activity or waking parameters (Fig. 7G; Table 1). The time spent in SWS2, however, increased during the first $3 \mathrm{hr}$, at the expense of SWS1 and W (Table 1).

\section{DISCUSSION}

The hypothesis that histaminergic neurons play a key role in arousal has been supported by recent investigations. Histaminergic neurons are thought to promote cortical activation and $\mathrm{W}$ via their ascending efferents, i.e., via a direct cortical projection or via a thalamo- or basalocortical pathway, as well as via a tonic control 


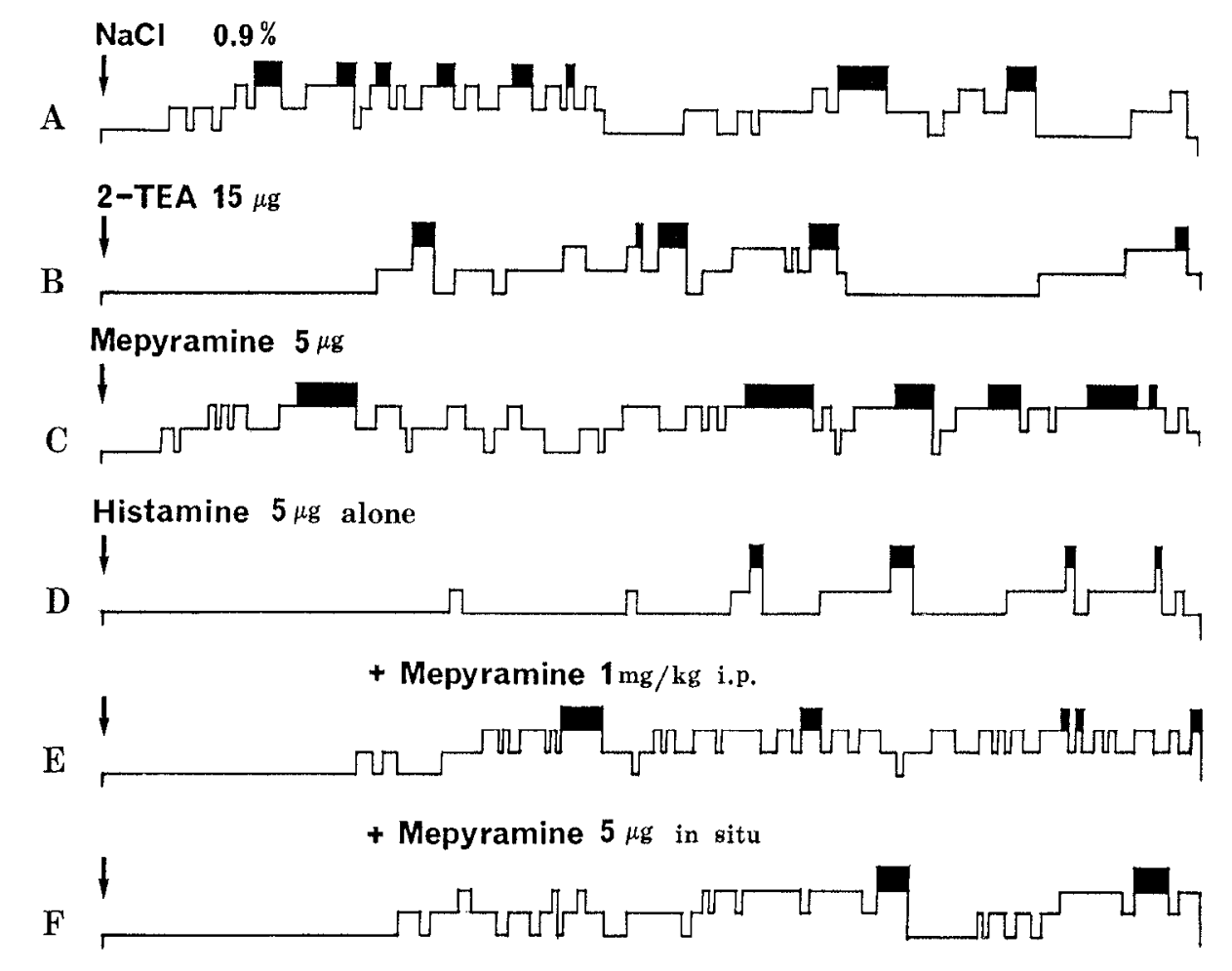

Figure 7. Representative 4 hr hypnograms obtained after microinjection of HA agonists and antagonist into the cat mediodorsal pontine tegmentum. In $E$ and $F$, mepyramine was administrated 30 or $5 \mathrm{~min}$, respectively, before HA microinjection. Abscissa indicates time (in $\mathrm{hr}$ ); ordinate indicates sleep-wake stages $(P S$, paradoxical sleep; $S W S 2$, deep slow wave sleep; SWS1, light slow wave sleep; $W$, wakefulness).

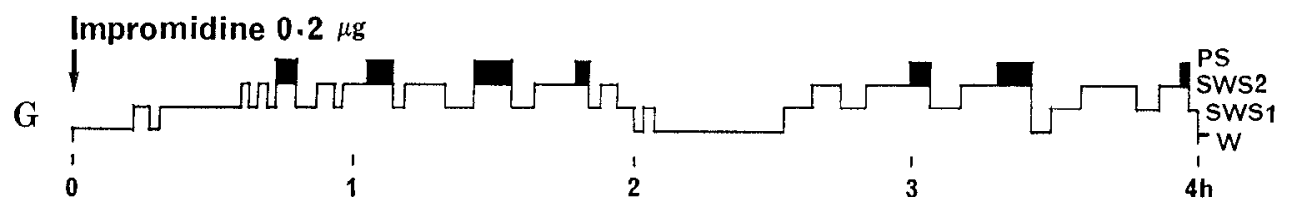

over the sleep-generating mechanisms in the preoptic/anterior hypothalamus (see introductory remarks). The main findings of the present study are that histaminergic neurons in the posterior hypothalamus send heavy fiber projections to the MPT, which is where cholinergic and noradrenergic neurons are located, and that these descending inputs could trigger cortical desynchronization by interaction with local neuronal elements. Our study thus points out that cortical activation is achieved not only by the well known ascending activating systems but also by descending mechanisms, such as histaminergic inputs to the MPT.

\section{Histaminergic descending inputs to the MPT}

From a functional viewpoint, the posterior hypothalamus has long been referred to as an important structure in brain arousal (Moruzzi, 1972; Sakai ct al., 1990a), whercas the MPT is known to be associated with the generation of W and PS (Jouvet, 1972; Sakai, 1988; Jones, 1990; Steriade et al., 1990). Their anatomical connections, therefore, have received much attention. Early tracing studies have demonstrated that the TM nucleus and adjacent structures project to the MPT (Sakai et al., 1977, 1983). Because HA neurons have been identified in this region, the question arises as to whether these hypothalamic descending inputs are histaminergic. Although a moderate to quite high density of HA fibers in the LC and surrounding areas has been mentioned in previous investigations in rodents (Airaksinen and Panula, 1988; Inagaki et al., 1988) and rabbits (Iwase et al., 1993), these systematic studies were not specifically focused on the MPT, and thus the data obtained concerning this region were not sufficiently precise to allow a comparison to be made with our study. Furthermore, the descending course of HA neurons to the MPT had not yet been demonstrated. In the present study, the combination of a highly sensitive HA antibody with improved second (biotinylated IgG) and third (streptavidin) antibodies and the use of nickel ammonium sulfate to intensify the peroxidase reaction enabled us to visualize the descending pathways of histaminergic neurons on parasagittal sections and to provide detailed information regarding their topographical distribution and morphology within the cat MPT.

The main histaminergic afferents to the MPT arise from both the ventral and the dorsal bundles. The ventral descending bundle seems to have a trajectory similar to that described previously for forebrain and hypothalamic descending projections to the brainstem in several species (Enoch and Kerr, 1967; Veazey et al., 1982; Simerly and Swanson, 1988). This bundle should also contain ascending fibers, because numerous cholinergic fibers from the MPT pass through the ventral mesencephalon while ascending to the posterior hypothalamus (Sakai et al., 1990a,b). The integrity of ascending and descending fibers contained in this ventral bundle, and thus the reciprocal link between the posterior hypothalamus and the MPT, should be of crucial importance in cortical activation. In fact, intercollicular transection (cerveau-isolé), spar ing the ventral mesencephalon, allows cortical desynchronization to persist, and only a complete transection causes a permanent synchronization (Moruzzi, 1972).

The histaminergic descending axons reach the MPT and form a dense network of very fine and varicose fibers and terminal-like structures. These results are consistent with those obtained in a recent tracing study in the cat showing that injection of cholera toxin-B into the MPT causes retrograde labeling of histaminergic 
Drug and dose

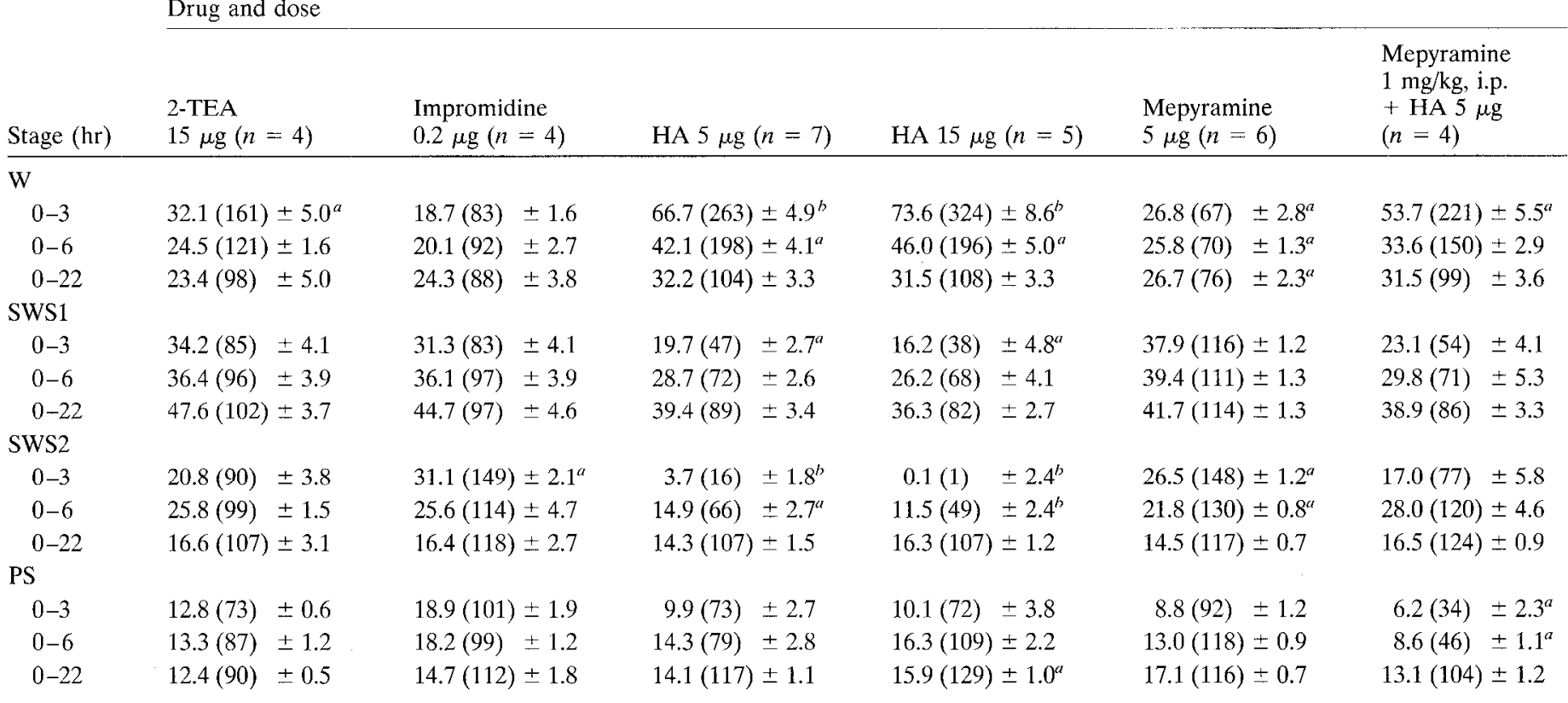

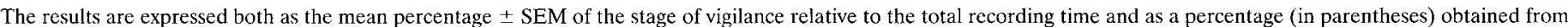

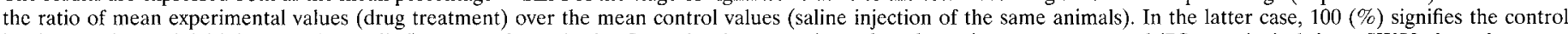

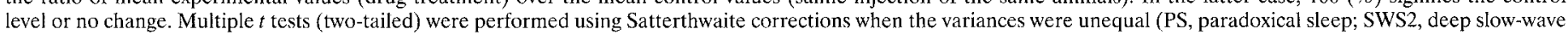
sleep; SWS1, light slow-wave sleep; W, wakefulness.

${ }^{a} p<0.05 ;{ }^{b} p<0.01$.

perikarya (Sakai, 1991). These data, taken together with the presence of dense HA receptors in the rodent MPT (Schwartz et al., 1991), leave little doubt that MPT neurons receive a descending histaminergic innervation from the posterior hypothalamus. Furthermore, we have studied the interactions between HA axon terminals and MPT neurons at the light microscopy level. HA terminal-like structures were found in intimate proximity to both cholinergic and noradrenergic neurons and seemed to make contact with them, suggesting that the activity of these neurons is under the influence of HA neurons. Although these results need to be confirmed by ultrastructural studies, electrophysiological data support the existence of a histaminergic control over pontomesencephalic cholinergic neurons, because HA excites these cells on guinea pig brain slices (Khateb et al., 1990). The available data, however, do not seem to support a direct histaminergic control over noradrenergic neurons. According to Haas et al. (1991), perfusion of brainstem slices with HA causes little change in the membrane potential and resistance of LC noradrenergic neurons. Thus, the topographical interactions shown here between HA terminals and noradrenergic perikarya may perhaps only allow HA to modulate their excitability, as that observed with hippocampal slices (Haas, 1992). Indeed, pharmacological studies also suggest a modulatory role for $\mathrm{HA}$ on noradrenaline release (Phillipu et al., 1984; Bealer, 1993).

\section{MPT histaminergic inputs and sleep-wake states}

Based on our anatomical data, we suggest that microadministration of HA into the mediodorsal pontine tegmentum can mimic the local release of endogenous HA from the descending terminals under physiological conditions and that the use of this approach may thereby permit an evaluation of their functional role in the control of cortical activity and sleep-wake states. HA microinjection disrupts cortical synchronized spindles and slow oscillations and enhances fast rhythms (known to occur during increased vigilance), causing a quiet waking state. The same effects were also observed using the microdialysis technique, which has several advantages over conventional microinjection (see Materials and Methods). These results suggest that the role of released IIA in the MPT is to trigger cortical desynchronization, to participate in its maintenance, and to increase alertness. Moreover, the HA-induced desynchronization and W in the MPT are the most prominent of the central targets that we have studied up to the present. Thus, of the different projections of HA neurons, those to the MPT seem to be the most important in histaminergic arousal mechanisms.

'The role of $\mathbf{H}_{1}$ receptors in histaminergic arousal is well documented. The administration of diverse centrally penetrating $\mathrm{H}_{1}$ receptor antagonists induces scdation and SWS (Lin ct al., 1986b, 1988; Monti et al., 1991). Autoradiographic studies have revealed the presence of a large number of $\mathrm{H}_{1}$ receptors in the rodent MPT (Bouthenet et al., 1988). The present study shows that the effects of $\mathrm{HA}$ can be mimicked by an $\mathrm{H}_{1}$-receptor agonist (2-TEA), that mepyramine (an $\mathrm{H}_{1}$ antagonist) elicits the opposite effect when injected into the same area, and that impromidine (an $\mathrm{H}_{2}$ agonist) had no effect on either $W$ or cortical activity. Furthermore, the effects of HA could be attenuated by systemic or local pretreatment with mcpyraminc. These effects seem therefore to be mediated by $H_{1}$ receptors, and the MPT could be one of the most important sites for the well known SWS-inducing effect of systemically administered $\mathrm{H}_{1}$-receptor antagonists. Cellular excitation induced by $\mathrm{H}_{1}$-receptor activation has been observed in many brain targets, including hypothalamic neurons in vivo (Haas, 1985) and many cell types in vitro, such as cortical (Reiner and Kamondi, 1994) and thalamic (McCormick and Williamson, 1991) neurons, as well as neurons in the substantia innominata (Khateb et al., 
1995) and the vestibular (Serafin et al., 1993) and pedunculopontine (Khateb et al., 1990) nuclei. Activation of $\mathrm{H}_{1}$ receptors usually causes slow membrane depolarization via the current $I_{\mathrm{KL}}$. It seems likely, therefore, that both HA-induced cortical desynchronization and $\mathrm{W}$ are attributable to an activation of MPT neurons via $\mathrm{H}_{1}$ receptors. Because several populations of neurons are present in this region, it remains to be determined which neuronal targets are activated that permit $\mathrm{H} \Lambda$ to elicit cortical desynchronization.

Brainstem noradrenergic neurons (A1-A7 groups) play an important role in the permissive mechanisms of PS and in the modulation of behavioral and cortical arousal, as well as in certain cognitive aspects of W (Jouvet, 1972; Foote et al., 1983; McGinty and Siegel, 1983; Jones, 1989). Could HA descending inputs trigger $\mathrm{W}$ and cortical desynchronization by activating noradrenergic neurons? As discussed above, currently available data do not favor an excitatory role of HA on LC noradrenergic neurons. On the other hand, even if local application of HA had elicited excitation of noradrenergic neurons under our experimental conditions, this should have led preferentially to PS suppression as a result of enhanced permissive mechanisms. However, our results show that the most potent effect of HA is SWS suppression. PS decreased only during the first $1-2 \mathrm{hr}$, when the waking effect was maximal. Moreover, our injection sites were aimed at the areas of the $\mathrm{LC} \alpha /$ peri-LC $\alpha$, probably affecting only a part of the noradrenergic neurons within the LC and not those of adjacent areas. LC noradrenergic neurons alone do not seem to play a primordial role in arousal, because lesions confined to this nucleus of cats do not cause a major deficit of W (Jones et al., 1977) and because administration of [ $N$-(2-chloroethyl)- $N$-ethyl-2-bromobenzylamine], which selectively destroys the noradrenergic ascending fibers emanating from the rat LC, does not significantly alter waking parameters (Valatx et al., 1991). Thus, there are actually no arguments in favor of a special link between the histaminergic afferents to the LC noradrenergic neurons and cortical activation. The possibility that HA descending inputs influence the sleepwake cycle via modulation of noradrenergic neurons outside the LC remains to be determined.

Alternatively, as indicated above, histaminergic descending inputs to the MPT are in a position to control, via $\mathrm{H}_{1}$ receptors, the activity of mesopontine cholinergic neurons, the role of which in diverse phenomena of $\mathrm{W}$ and PS is well documented (Jouvet, 1975; El Mansari et al., 1989; Steriade et al., 1990; Jones, 1993). These neurons may constitute important targets for histaminergic arousal. Some pontine PS-on cells are presumably cholinergic in nature. It is unlikely, however, that HA application to the MPT activates these cells, because PS was not enhanced by IIA or the $\mathrm{H}_{1}$ agonist during the induced cortical desynchronization. In contrast, a constellation of presumed cholinergic neurons, with a tonic activity specific to neocortical desynchronization (tonic type I cells), has been identified in the cholinergic MPT such as the $\mathrm{LC} \alpha$ and peri-LC $\alpha$ in which our microinjections were made. These neurons project to the posterior hypothalamus and/or thalamic intralaminar nuclei and significantly increase their discharge rate just before the onset of cortical desynchronization of $W$ and maintain their tonic activity throughout the entire episode, suggesting that they constitute a mesopontine excitatory source for cortical activation (El Mansari et al., 1989; Steriade et al., 1990). Thus, the complete cortical desynchronization and associated long-lasting $\mathrm{W}$ induced by HA microinjection, as well as the subsequent slight rebound in PS, could be interpreted as preferential activation by $\mathrm{HA}$ of the presumed cholinergic and ascend- ing tonic neurons around the injection sites. In addition, activation by $\mathrm{HA}$ of cholinergic PGO-on cells near the injection loci might also contribute to the observed effects, because these cells also discharge tonically during $W$ and project to the thalamus (Sakai, 1980). In support of our interpretation, Khateb et al. (1990) demonstrated on guinea pig brain slices that HA excites tegmental cholinergic neurons by direct depolarization via $\mathrm{H}_{1}$ receptors. The findings that HA microinjection into the peri-LC $\alpha$ and rostral LC $\alpha$ (where a majority of tonic ascending neurons are located) induces a greater waking effect than that induced by injection into the LC and caudal LC $\alpha$ (containing mainly noradrenergic cells) are also in keeping with this hypothesis. Furthermore, according to Steriade et al. (1991, 1993), electrical stimulation of PPT nuclei disrupts cortical slow oscillation and elicits fast activity through muscarinic actions on the thalamus. These data, comparable with those obtained after intrategmental HA application, support the importance of cholinergic mesopontinethalamic mechanisms in cortical activation and in the HA-induced arousal. Although not all MPT tonic neurons are cholinergic in nature and consequently there might be other local HA targets, all of these results suggest that HA descending afferents in the MPT could promote the occurrence of cortical desynchronization and W, at least partially, via activation of $H_{1}$ receptors situated on cholinergic neurons.

In addition, a permissive control by the posterior hypothalamus over the pontine executive mechanisms of PS has been suggested, because lesions of this structure (Sallanon et al., 1988) or inactivation of its caudal part (Lin et al., 1989) causes PS hypersomnia. The exclusive presence of HA neurons in the posterior hypothalamus, their projections to the MPT, and the waking-specific and PS-off pattern of presumed IIA neurons lead to the assumption that this permissive control may be histaminergic. A histaminergic inhibitory role on PS would have been established if the pontine HA inputs had excited the PS-permissive mechanisms (catecholaminergic neurons) or inhibited its executive systems (cholinergic/cholinoceptive mechanisms). Because neither of these has yet been demonstrated by diverse electrophysiological studies (Haas et al., 1991; Haas, 1992), however, and because in this study neither HA agonists nor antagonist affected PS in a marked and selective manner, we suggest that histaminergic neurons may exert an inhibitory role on PS by their arousal effects via cholinergic tonic neurons, and that this dominant arousal might explain why PS was not enhanced by activation of tonic neurons by HA.

\section{Interactions of histaminergic and cholinergic neurons in the mechanisms of cortical activation}

So far, we have indicated a possible anatomical and functional link between histaminergic descending inputs and mesopontine cholinergic neurons. The interactions between the histaminergic and cholinergic systems, however, are not limited to the MPT. Recently, we have demonstrated in the cat that histaminergic neurons also send fiber projections to the substantia innominata and adjacent basal forebrain (Lin et al., 1993, 1994), which contain magnocellular cholinergic and noncholinergic neurons projecting to the neocortex that probably play an important role in cortical activation (Steriade and Buzsaki, 1990). Furthermore, bath application of HA to guinea pig brain slices also shifts these cholinergic and noncholinergic neurons from burst discharge to tonic activity (Fort et al., 1992; Khateb et al., 1995). Together, these data suggest that HA neurons may promote cortical activation via the cholinergic system by a dual activation: that of the corticopetal system originating from the basal forebrain and that of the pon- 


\section{Cerebral Cortex}
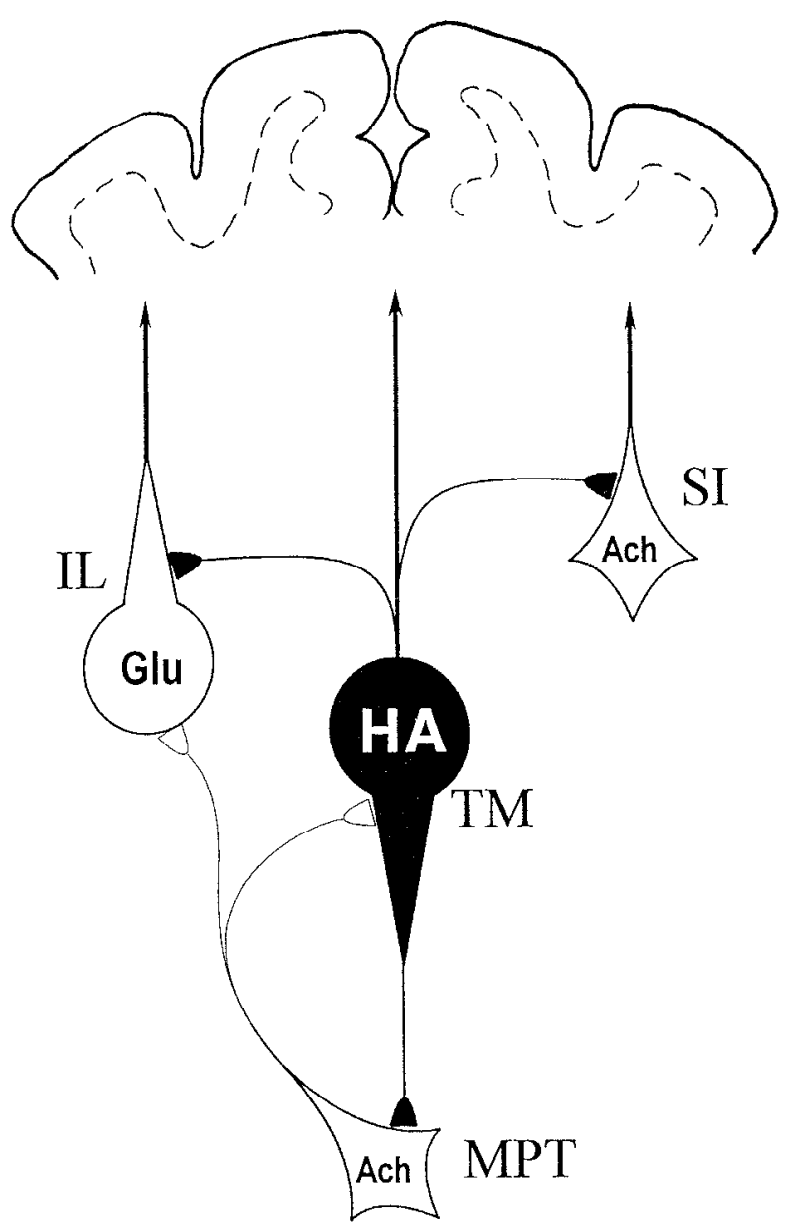

Figure 8. Schematic circuitry representing our hypothesis concerning the multiple interactions between histaminergic and cholinergic neurons with respect to the neocortical activation of $W$. This hypothesis can be summarized as follows. Neocortical activation during $\mathrm{W}$ is ensured by the excitatory corticopetal projections (arrows) arising mainly from three subcortical structures, i.e., the thalamus, posterior hypothalamus, and basal forebrain, and from brainstem aminergic neurons (not shown). These subcortical systems are represented here, respectively, by the presumed glutamatergic $(G l u)$ intralaminar nuclei $(I L)$, the histaminergic (HA) $T M$, and the cholinergic $(A c h)$ substantia innominata $(S I)$. The thalamic IL and hypothalamic TM nuclei receive ascending excitatory afferents from the MPT cholinergic neurons $(A C h)$. Histaminergic neurons can activate the cortex either directly by their widespread hypothalamocortical projection or indirectly via the thalamocortical system. In addition, they could promote cortical activation via the cholinergic system by a dual activation: that of the corticopetal system, originating from the SI, and that of the pontothalamic or pontohypothalamic systems, arising from the $M P T$ group. The excitatory interactions between histaminergic and cholinergic neurons in the MPT, posterior hypothalamus, and basal forebrain constitute a crucial circuit within the whole ascending network responsible for the maintenance of cortical activation and $\mathrm{W}$.

tothalamic or pontohypothalamic systems arising from the MPT (Fig. 8). The possibility that HA descending inputs interact with cholinergic cells situated in the medulla magnocellular reticular formation remains to be investigated.

In a manner reciprocal with that of the HA descending inputs, pontomesencephalic cholinergic neurons send ascending projections to the TM nucleus and adjacent regions, as well as to the thalamic intralaminar nuclei (Steriade et a1., 1988; Sakai et al., 1990a), an important relay for transmission of brainstem excitatory influx to the neocortex (Steriade and Glenn, 1982). As seen after microadministration of $\mathbf{H A}$ or its $\mathbf{H}_{1}$ agonist into the cholinergic MPT, microinjection or microdialysis of carbachol, a muscarinic receptor agonist, into these two structures suppresses cortical slow activity and induces W. PS episodes persist, but the total amount decreases (Sakai et al., 1990a) (our unpublished data). Although the cxact cellular action of cholinergic inputs on histaminergic neurons remains to be verified, these results suggest that cholinergic ascending inputs to the posterior hypothalamus and intralaminar nuclei, in turn, constitute important excitatory afferents for the thalamo- and hypothalamocortical systems and thus for ascending cortical activation (Fig. 8).

$\mathrm{W}$ is a brain functional state allowing the performance of several so called "high brain functions" such as diverse behavioral, cognitive, and emotional activities. Current data at the wholeanimal and cellular level suggest that the maintenance of the cerebral cortex in this highly complex state necessitates the convergent and divergent activity of an ascending network within a large reticular zone extending from the medulla to the forebrain, implicating several neurotransmitters such as HA, acetylcholine, noradrenaline, and glutamate (North, 1986; Jones, 1989; McCormick and Williamson, 1989; Nicoll et al., 1990). From a behavioral viewpoint, this convergent and divergent activity probably reflects the fact that each ascending neurotransmitter contributes commonly to the maintenance of cortical activation during $\mathrm{W}$, whereas in different behavioral or cognitive contexts their individual participation and specific functional role may be subtly distinct. We suggest that the multiple excitatory interactions between histaminergic and cholinergic neurons constitute a crucial circuit (Fig. 8) within the whole ascending network that is responsible for the maintenance of cortical activation and $W$. The specific behavioral and cognitive significance of these interactions, however, remains to be explored.

\section{REFERENCES}

Airaksinen M, Panula P (1988) The histaminergic system in the guinea pig central nervous system: an immunocytochemical mapping study using an antiserum against histamine. J Comp Neurol 273:163-186.

Angeleri F, Marchesi GF, Quattrini A (1969) Effects of chronic thalamic lesion on the electrical activity of the neocortex and on sleep. Arch Ital Biol 107:633-667.

Bealer SL (1993) Histamine releases norepinephrine in the paraventricular nucleus/anterior hypothalamus of the conscious rat. J Pharmacol Exp Ther 262:734-738.

Berman AL (1968) The brain stem of the cat: a cytoarchitectonic atlas with stereotaxic coordinates. Madison: University of Wisconsin.

Bouthenet ML, Ruat M, Sales N, Garbarg M, Schwartz JC (1988) A detailed mapping of histamine H1-receptors in guinea-pig central nervous system established by autoradiography with [ $\left.{ }^{125} \mathrm{I}\right]$ iodobolpyramine. Neuroscience 26:553-600).

Bremer F (1935) Cerveau "isolé" et physiologie du sommeil. C R Soc Biol (Paris) 118:1235-1242.

Buzsaki G, Bickford RG, Ponomareff G, Thal LJ, Mandel R, Gage FH (1988) Nucleus basalis and thalamic control of neocortical activity in the freely moving rat. J Neurosci 8:4007-4026.

Denoyer M, Sallanon M, Buda C, Kitahama K, Jouvet M (1991) Neurotoxic lesion of the mesencephalic reticular formation and/or the posterior hypothalamus does not alter waking in the rat. Brain Res 539:287-303.

Durant GJ, Duncan WAM, Ganellin CR, Parsons ME, Blakemore RC, Rasmussen AC (1978) Impromidine ( $S K \& F$ 92676) is a very potent and specific agonist for histamine $\mathrm{H}_{2}$ receptors. Nature 276:403-405.

El Mansari M, Sakai K, Jouvet M (1989) Unitary characteristics of presumptive cholinergic tegmental neurons during the sleep-waking cycle in freely moving cats. Exp Brain Res 76:519-529. 
Enoch DM, Kerr FWL (1967) Hypothalamic vasopressor and vesicopressor pathways. II. Anatomic study of their course and connections. Arch Neurol 16:307-320.

Foote SL, Bloom FE, Aston-Jones G (1983) Nucleus locus coenuleus: new evidence of anatomical and physiological specificity. Physiol Rev 63:844-914.

Gross PM (1982) Ccrcbral histaminc: indications for ncuronal and vascular regulation. J Cereb Blood Flow Metab 2:3-23.

Fort P, Khateb A, Alonso A, Jones BE, Mühlethaler M (1992) Pharmacological heterogeneity of basal forebrain neurones. Soc Neurosci Abstr $18: 336$.

Haas HL (1985) Histamine. In: Neurotransmitter actions in the vertebrate nervous system (Rogawski MA, Barker JL, eds), pp 321-337. New York: Plenum.

Haas HL (1992) Electrophysiology of histamine-receptors. In: The histamine receptors (Schwartz JC, Haas HL, eds), pp 161-178. New York: Wiley-Liss.

Haas HL, Reiner PB, Greene RW (1991) Histaminergic and histaminoceptive neurons: electrophysiological study in vertebrates. In: Histaminergic neurons: morphology and function (Watanabe $\mathrm{T}$, Wada $\mathrm{H}$, eds), pp 195-208. Boca Raton, FL: CRC.

Inagaki N, Yamatodani A, Ando-Yamamoto M, Tohyama M, Watanabe T, Wada H (1988) Organization of histaminergic fibers in rat brain. J Comp Neurol 273:283-300.

Iwase MI, Homma I, Shioda S, Nakai Y (1993) Histamine immunoreactive neurons in the brain stem of the rabbit. Brain Res Bull 32:267-272.

Jones BE (1989) Basic mechanisms of sleep-wake states. In: Principles and practice of sleep medicine (Kryger MH, Roth T, Dement WC, eds), pp 121-138. Philadelphia: Saunders.

Jones BE (1990) Influence of the brainstem reticular formation, including intrinsic monoaminergic and cholinergic neurons, on forebrain mechanisms of sleep and waking. In: The diphencephalon and sleep (Mancia M, Marini G, eds), pp 31-48. New York: Raven.

Jones BE (1993) The organization of central cholinergic systems and their functional importance in sleep-waking states. In: Progress in brain research, Vol 98 (Cuello AC, ed), pp 61-71. Amsterdam: Elsevier Science.

Jones BE, Beaudet A (1987) Distribution of acetylcholine and catecholamine neurons in the cat brainstem: a choline acetyltransferase and tyrosine hydroxylase immunohistochemical study. I Comp Neurol $261: 15-32$.

Jones BE Harper ST, Halaris AE (1977) Effects of locus coeruleus lesions upon cercbral monoaminc content, slcep-wakefulness states and the response to amphetamine in the cat. Brain Res 124:473-496.

Jouvet M (1972) The role of monoamines and acetylcholine containing neurons in the regulation of the sleep-waking cycle. Ergeb Physiol Biol Chem Exp Pharmakol 64:166-307.

Jouvet M (1975) Cholinergic mechanisms and sleep. In: Cholinergic mechanisms (Waser P, ed), pp 455-476. New York: Raven.

Juhasz G, Kékesi K, Emri Z, Soltesz I, Crunelli V (1990) Sleeppromoting action of excitatory amino acid antagonists: a different role for thalamic NMDA and non-NMDA receptors. Neurosci Lett 114:333-338.

Khateb A, Fort P, Pegna A, Jones BE, Mühlethaler M (1995) Cholinergic nucleus basalis neurons are excited by histamine in vitro. Neuroscience 69:495-506.

Khateb A, Serafin M, Mühlethaler M (1990) Histanime excites pedunculopontine neurones in guinea pig brainstem slices. Neurosci Lett 112:257-262.

Krilowiicz BL, Szymusiak R, McGinty D (1995) Regulation of posterior lateral hypothalamus arousal related neuronal discharge by preoptic anterior hypothalamic warming. Brain Res 668:30-38.

Lin JS, Fort P, Kitahama K, Panula P, Denney RM, Jouvet M (1991) Immunohistochemical evidence for the presence of type $\mathrm{B}$ monoamine oxidase in histamine containing neurons in the posterior hypothalamus of cats. Neurosci Lett 128:61-65.

Lin JS, Kitahama K, Fort P, Panula P, Denney RM, Jouvet M (1993) IIistaminergic system in the posterior hypothalamus in the cat with reference to type B monoamine oxidase. J Comp Neurol 330:405-420.

Lin JS, Luppi PH, Salvert D, Sakai K, Jouvet M (1986a) Histaminecontaining neurons in the cat hypothalamus. $\mathrm{C} R$ Acad Sci (III) 303:371-376.

Lin JS, Sakai K, Jouvet M (1986b) Role of hypothalamic histaminergic systems in the regulation of the states of vigilance in the cat. C R Acad Sci (III) 303:469-474.
Lin JS, Sakai K, Jouvet M (1988) Evidence for histaminergic arousal mechanisms in the hypothalamus of cats. Neuropharmacology 27:111-122.

Lin JS, Sakai K, Jouvet M (1994) Hypothalamo-prenptic histaminergic projections in sleep-wake control in the cat. Eur $\mathbf{J}$ Neurosci 6:618-625.

Lin JS, Sakai K, Vanni-Mercier G, Arrang JM, Garbarg M, Schwartz JC, Jouvet M (1990) Involvement of histamincrgic ncurons in arousal mechanisms demonstrated with $\mathrm{H}_{3}$-receptor ligands in the cat. Brain Res 523:325-330.

Lin JS, Sakai K, Vanni-Mercier G, Jouvet M (1989) A critical role of the posterior hypothalamus in the mechanisms of wakefulness determined by microinjection of muscimol in freely moving cats. Brain Res 479:225-240.

Maeda T, Pin C, Salvert D, Ligier M, Jouvet M (1973) Les neurones contenant des catécholamines du tegmentum pontique et leurs voies de projection chez le chat. Brain Res 57:119-152.

McCormick DA, Williamson A (1989) Convergence and divergence of neurutransmitter action in human cerebral cortex. Proc Natl Acad Sci USA 86:8098-8102.

McCormick DA, Williamson A (1991) Modulation of neuronal firing mode in cat and guinea pig LGNd by histamine: possible cellular mechanisms of histaminergic control of arousal. J Neurosci 11:3188-3199.

McGinty DJ, Siegel JM (1983) Sleep states. In: Handbook of behavioral neurobiology: motivation (Satinoff E, Teitelbaum P, eds), pp 105-181. New York: Plenum.

Monti JM, Jantos H, Boussard M, Altier H, Orellana C, Olivera S (1991) Effects of selective activation or blockade of the histamine $\mathrm{H}_{3}$ receptor on sleep and wakefulness. Eur J Pharmacol 205:283-287.

Moruzzi G (1972) The sleep-waking cycle. Ergeb Physiol Biol Chem Exp Pharmacol 64:1-165.

Moruzzi G, Magoun HW (1949) Brainstem reticular formation and activation of the EEG. Electroencephalogr Clin Neurophysiol 1:455-473.

Naquet R, Denavit M, Lanoir J, Albe-Fessard D (1965) Altérations transitoires ou définitives de zones diencéphaliques chez le chat: leurs effets sur l'activité électrique corticale et le sommeil. In: Aspects anatomo-fonctionnels de la physiologie du sommeil (Jouvet M, ed), pp 103-11. Paris: Centre National de la Recherche Scientifique.

Nicoll RA, Malenka RC, Kauer JA (1990) Functional comparison of neurotransmitter receptor subtypes in mammalian central nervous system. Physiol Rev 70:513-565.

North RA (1986) Receptors on individual neurones. Neuroscience 17:899-907.

Onoé H, Watanabe Y, Ono K, Koyama Y, Hayashi O (1992a) Prostaglandin E2 exerts an awaking effect in the posterior hypothalamus at a site distinct from that mediating its febrile action in the anterior hypothalamus. J Neurosci 12:2715-2725.

Onoé II, Yamatodani A, Watanabc Y, Mochizuki T, Wada H, Hayashi O (1992b) Prostaglandin E2 and histamine in the posterior hypothalamus. J Sleep Res 1[Suppl 1]:166.

Panula P, Häppolä O, Airaksinen S, Auvinen S, Virkamäki A (1988) Carbodiimide as a tissue fixative in histamine immunohistochemistry and its application in developmental neurobiology. J Histochem Cytochem 36:259-269.

Panula P, Pirvola U, Auvinen S, Airaksinen MS (1989) Histamineimmunoreactive nerve fibers in the rat brain. Neuroscience 28:585-610.

Petitjean F, Sakai K, Blondaux C, Jouvet M (1975) Hypersomnie par lésion isthmique chez le chat. II. Etude neurophysiologique et neuropharmacologique. Brain Res 88:439-453.

Philippu A, Bald M, Kraus A, Dietl H (1984) In vivo release by histamine agonists and antagonists of endogenous catecholamines in the cat hypothalamus. Naunyn Schmiedebergs Arch Pharmacol 326:116-123.

Reiner PB, Kamondi A (1994) Mechanisms of antihistamine-induced sedation in the human brain: $\mathrm{H}_{1}$ receptor activation reduces a background leakage potassium current. Neuroscience 59:579-588.

Reinoso-Suárez F (1961) Topographischer hirnatlas der katze für experimentalphysiologische untersuchungen. Darmstadt: Merck.

Sakai K (1980) Some anatomical and physiological properties of pontomesencephalic tegmental neurons with special reference to the PGO waves and postural atonia during paradoxical sleep in the cat. In: The reticular formation revisited (Hobson JA, Brazier MB, eds), pp 427 447. New York: Raven.

Sakai K (1988) Executive mechanisms of paradoxical sleep. Arch Ital Biol 479:225-240. 
Sakai K (1991) Physiological properties and afferent connections of the locus coeruleus and adjacent tegmental neurons involved in the generation of paradoxical sleep in the cat. In: Progress in brain research, Vol 88, Neurophysiology of the locus coeruleus (Barnes CD, Pompeiano O, eds), pp 31-45. Amsterdam: Elsevier Science.

Sakai K, El Mansari M, Lin JS, Zhang JG, Vanni-Mercier G (1990a) The postcrior hypothalamus in the regulation of wakcfulncss and paradoxical sleep. In: The diphencephalon and sleep (Mancia M, Marini G, eds), pp 171-198. New York: Raven.

Sakai K, Luppi PH, Salvert D, Kimura H, Maeda T, Jouvet M (1986) Localisation of cholinergic neurons in the cat lower brain stem. C R Acad Sci (III) 303:317-324.

Sakai K, Salvert D, Kimura H, Maeda T, Jouvet M (1983) Ascending and descending projections of caudal hypothalamic neurons stained by serotoine immunohistochemistry after administration of 5hydroxytryptophan in the cat. C R Acad Sci (III) 296:1013-1018.

Sakai K, Touret M, Salver D, Léger L, Jouvet M (1977) Afferent projections to the cat locus coeruleus as visualized by the horseradish peroxidase technique. Brain Res 119:21-41.

Sakai K, Yoshimoto Y, Luppi PH, Fort P, El Mansari M, Salvert D, Jouvet M (1990b) Lowcr brainstem affercnts to the cat posterior hypothalamus: a double labeling study. Brain Res Bull 24:437-455.

Sallanon M, Denoyer M, Kitahama K, Aubert C, Gay N, Jouvet M (1989) Long-lasting insomnia induced by preoptic neuron lesions and its transient reversal by muscimol injection into the posterior hypothalamus in the cat. Neuroscience 32:669-683.

Sallanon M, Sakai K, Buda C, Puymartin M, Jouvet M (1988) Increase of paradoxical sleep induced by microinjections of ibotenic acid into the ventrolateral part of the posterior hypothalamus in the cat. Arch Ital Biol 126:87-97.

Schwartz JC (1979) Histamine receptors in brain. Life Sci 25:895-912.

Schwartz JC, Arrang JM, Garbarg M, Pollard H, Ruat M (1991) Histaminergic transmission in the mammalian brain. Physiol Rev 71:1-51.

Serafin M, Khateb A, Vibert N, Vidal PP, Mühlethaler M (1993) Medial vestibular nucleus in the guinea-pig: histaminergic receptors. I. An in vitro study. Exp Brain Res 93:242-248.

Simerly RB, Swanson LW (1988) Projections of the medial preoptic nucleus: a phaseolus vulgaris leucoagglutinin anterograde tract-tracing study in the rat. J Comp Neurol 270:209-241.

Steriade M (1991) Alertness, quiet sleep, dreaming. In: Cerebral cortex, Vol. 9 (Peters A, ed), pp 279-357. New York: Plenum.

Steriade M, Buzsaki G (1990) Parallel activation of thalamic and cortical neurons by brainstem and basal forebrain cholinergic system. In: Brain cholinergic systems (Steriade M, Biesold D, eds), pp 3-64. New York: Oxford UP.

Steriade M, Glenn LL (1982) Neocortical and caudate projections of intralaminar thalamic neurons and their synaptic excitation from midbrain reticular core. J Neurophysiol 48:352-371.
Steriade M, Amzica F, Nunez A (1993) Cholinergic and noradrenergic modulation of the slow $(\approx 0.3 \mathrm{~Hz})$ oscillation in neocortical cells. J Neurophysiol 70:1385-1400.

Steriade M, Curro Dossi R, Paré D, Oakson G (1991) Fast oscillations $(20-40 \mathrm{~Hz})$ in the thalamocortical systems and their potentiation by mesopontine cholinergic nuclei in the cat. Proc Natl Acad Sci USA 88:4396-4400.

Steriade M, Datta S, Paré D, Oakson G, Curro Dossi R (1990) Neuronal activity in brainstem cholinergic nuclei related to activation process in thalamocortical systems. J Neurosci 10:2541-2559.

Steriade M, Paré D, Parent A, Smith Y (1988) Projections of cholinergic and non-cholinergic neurons of the brainstem core to relay and associational thalamic nuclei in the cat and macaque monkey. Neuroscience 25:47-67.

Sternberger LA, Joseph SA (1979) The unlabeled antibody method: contrasting color staining of paired pituitary hormones without antibody removal. J Histochem Cytochem 27:1424-1429.

Swanson LW (1992) Brain maps: structures of the rat brain. Amsterdam: Elsevier.

Uhlrich DJ, Manning KA, Pienkowski TP (1993) The histaminergic innervation of the lateral geniculate complex in the cat. Vis Neurosci $10: 225-235$.

Valatx JL, Kitahama K, Jouvet M (1991) DSP-4: alteration of the rat sleep regulation. In: Sleep research, Vol 20A (Chase MH, Parmeggiani PL, O'Connor C, eds), p 590. Los Angeles: BIS/BRI, University of California.

Vanderwolf CH, Stewart DJ (1988) Thalamic control of neocortical activation: a critical reevaluation. Brain Res Bull 20:529-538.

Vanni-Mercier G, Sakai K, Lin JS, Jouvet M (1989) Mapping of cholinoceptive brainstem structures responsible for the generation of paradoxical sleep in the cat. Arch Ital Biol 127:133-164.

Vanni-Mercier G, Sakai K, Salvert D, Jouvet M (1984) “Waking-state specific" neurons in the caudal hypothalamus of the cat. C R Acad Sci (III) 298:195-200.

Veazey RB, Amaral DG, Cowan WM (1982) The morphology and connections of the posterior hypothalamus in the cynomolgus monkey (Macaca fascicularis). II. Efferent connections. J Comp Neurol 207:135-156.

Villablanca J (1974) Role of the thalamus in sleep control: sleepwakefulness in chronic diencephalic and athalamic cats. In: Basic sleep mechanisms (Petre-Quadens O, Schlag JD, eds), pp 51-78. New York: Academic.

Vincent ST, Reiner PB (1987) The immunohistochemical localization of choline acetyltransferase in the cat brain. Brain Res Bull 18:371-415.

Wiklund L, Léger L, Persson M (1981) Monoamine cell distribution in the cat brain stem: a fluorescence histochemical study with quantification of indolaminergic and locus coeruleus cell groups. J Comp Neurol 203:613-647. 